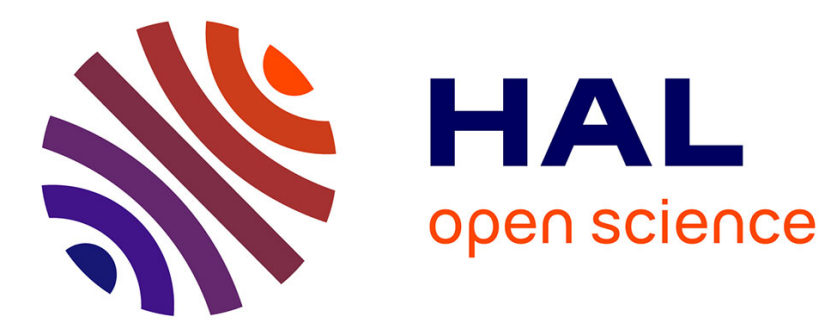

\title{
Nondilatant brittle deformation of serpentinites: Implications for Mohr-Coulomb theory and the strength of faults
}

J. Escartin, G. Hirth, B. Evans

\section{- To cite this version:}

J. Escartin, G. Hirth, B. Evans. Nondilatant brittle deformation of serpentinites: Implications for Mohr-Coulomb theory and the strength of faults. Journal of Geophysical Research, 1997, 102 (B2), pp.2897-2913. 10.1029/96JB02792 . insu-01876085

HAL Id: insu-01876085

https://hal-insu.archives-ouvertes.fr/insu-01876085

Submitted on 18 Sep 2018

HAL is a multi-disciplinary open access archive for the deposit and dissemination of scientific research documents, whether they are published or not. The documents may come from teaching and research institutions in France or abroad, or from public or private research centers.
L'archive ouverte pluridisciplinaire $\mathbf{H A L}$, est destinée au dépôt et à la diffusion de documents scientifiques de niveau recherche, publiés ou non, émanant des établissements d'enseignement et de recherche français ou étrangers, des laboratoires publics ou privés. 


\title{
Nondilatant brittle deformation of serpentinites: Implications for Mohr-Coulomb theory and the strength of faults
}

\author{
J. Escartín ${ }^{1}$ and G. Hirth \\ Department of Geology and Geophysics, Woods Hole Oceanographic Institution, Woods Hole, Massachusetts
}

\section{B. Evans}

Earth, Atmospheric and Planetary Sciences, Massachusetts Institute of Technology, Cambridge, Massachusetts

\begin{abstract}
We conducted deformation experiments to investigate the strength, deformation processes, and nature of the brittle-ductile transition of lizardite and antigorite serpentinites. A transition from localized to distributed deformation occurs as confining pressure increases from $\sim 200$ to $\sim 400 \mathrm{MPa}$ at room temperature. Deformation in both brittle (localized) and ductile (distributed) regimes is accommodated by shear microcracks, which form preferentially parallel to the (001) cleavage. Axial microcracks (mode I) are infrequently observed. Volumetric strain measurements demonstrate that brittle deformation is mostly nondilatant, consistent with the shear-dominated microcracking. Three observations indicate that deformation in the ductile regime is accommodated by cataclastic flow: (1) a lack of evidence for crystal plastic deformation, (2) a positive pressure dependence of the maximum differential stress, and (3) abundant evidence for brittle microcracking. The weakness of serpentinites relative to other brittle rocks is explained by a low fracture strength along the (001) cleavage, combined with the low pressure dependence of strength. The transition from brittle to ductile deformation occurs at the crossover between the strength of intact serpentinite and the friction law unique to each type of serpentinite, rather than the more general Byerlee's law. If brittle deformation regimes are defined based on the mode of microcracking and on the occurrence of crystal plasticity, serpentinites define an end-member style of nondilatant brittle deformation. This deformation style may result in extremely weak faults in nature, and it may also strongly influence the tectonic evolution of the oceanic lithosphere where serpentinite is present.
\end{abstract}

\section{Introduction}

Serpentine is probably the most abundant alteration phase in ultramafic rocks from the oceanic lithosphere [e.g., Aumento and Loubat, 1971; Bonatti, 1976]. Such alteration products can influence the rheological properties of shear zones [e.g., Vernon, 1977; Brodie and Rutter, 1985; Mével and Cannat, 1992; Gillis et al., 1993]. However, rheological models [e.g., Chen and Molnar, 1983; Lin and Parmentier, 1989; Neumann and Forsyth, 1993] do not include these phases, owing partly to the scarcity of mechanical data, but also to a lack of information on their distribution and abundance. Instead, lithospheric strength is typically modeled using Byerlee's friction law and experimental plastic flow laws for unaltered quartzite, diabase, and olivine [e.g., Brace and Kohlstedt, 1980; Kohlstedt et al., 1995].

The importance of serpentine for the tectonics of the oceanic lithosphere has been debated since at least the early 1960s when Hess [1962] proposed that oceanic layer 3 is composed mostly of serpentinites. Peridotites dredged or drilled along slow spreading mid-ocean ridges and fracture zones invariably show a high

\footnotetext{
'Now at Department of Geological Sciences, University of Durham, South Road, Durham, England.
}

Copyright 1997 by the American Geophysical Union.

Paper number 96JB02792.

0148-0227/97/96JB-02792\$09.00 degree of serpentinization [e.g., Aumento and Loubat, 1971; Bonatti, 1976; Dick, 1989; Cannat et al., 1992], indicating that hydration of peridotite occurs in very young $(<1 \mathrm{Ma})$ oceanic lithosphere. In addition, studies on the Josephine ophiolite have documented oceanic serpentinization of the lithosphere at or near the ridge axis [Coulton et al., 1995]. Consequently, the tectonics of slow spreading mid-ocean ridges, fracture zones, subduction zones, and obducted ophiolites are likely affected by the presence of serpentinites.

The serpentine group is composed of the polytypes lizardite, chrysotile, and antigorite. Lizardite, the most abundant serpentine mineral, occurs mainly in retrograde metamorphic assemblages [e.g., Moody, 1976; Wicks and Whittaker, 1977] and is common along mid-ocean ridges [Aumento and Loubat, 1971]. Antigorite is the second most abundant polytype and the main component of prograde serpentinites [e.g., Coleman, 1971; Wicks and Whittaker, 1977]. Antigorite and lizardite are stable at temperatures $<400^{\circ}-500^{\circ} \mathrm{C}$ [Caruso and Chernosky, 1979; Janecky and Seyfried, 1986; Ulmer and Trommsdorff, 1995] and lithospheric pressures. Chrysotile, the least abundant polytype, is stable below $300^{\circ} \mathrm{C}$ [Caruso and Chernosky, 1979; O'Hanley et al., 1989] and is a minor component of both prograde and retrograde serpentinites [Wicks and O'Hanley, 1988].

Previous experimental work shows that serpentinites are generally weaker than other common lithospheric rocks and that lizardite is weaker than antigorite. Raleigh and Paterson [1965, p. 3965] concluded that antigorite had an "... ultimate strength 
similar to that of granite at room temperature..." Unfortunately, this assertion has been generalized to all serpentinites, even though those experiments and subsequent work [Raleigh and Paterson, 1965;Murrell and Ismail, 1976] indicated that lizardite is considerably weaker than both antigorite and granite. The frictional strength of lizardite is also less than that of antigorite [Dengo and Logan, 1981; Reinen et al., 1994; Moore et al., 1995]; friction coefficients $(\mu)$ of lizardite gouge vary between $\mu=0.15-0.35$ [Reinen et al., 1994] and $\mu=0.4$ [Moore et al., 1995] and increase to $\mu=0.50-0.56$ for polished surfaces [Dengo and Logan, 1981]. The coefficient of friction is higher for both antigorite gouge $(\mu=0.5-0.85$ [Reinen et al., 1994], $\mu=0.47$ [Moore et al., 1995]) and polished surfaces $(\mu=0.77$ [Dengo and Logan, 1981]). Note that the lizardite used by Reinen et al. [1994] may have been mostly chrysotile instead of lizardite [Reinen and Tullis., 1995].

We conducted experiments on lizardite and antigorite to investigate the processes responsible for the transition from localized to distributed deformation and to determine why serpentinites are weaker than other lithospheric rocks. We measured volumetric strain and correlated the mechanical data with deformation microstructures. We observed a new style of mostly nondilatant brittle deformation. This style of deformation may substantially weaken serpentinite-bearing faults and thus control the mechanical evolution of the oceanic lithosphere where serpentinites are present.

\section{Experimental Details}

\section{Samples}

Antigorite serpentinite. We used an antigorite serpentinite (VM3) that is $\sim 90 \%$ antigorite, with less than $5 \% \mathrm{Fe}$ oxides, and minor amounts of magnesite along veins; this is the same material studied by Reinen et al. [1994]. The rock has a weak macroscopic foliation; bands of elongated antigorite grains $(<300$ $\mu \mathrm{m}$ in length) with basal planes parallel to the overall foliation (bladed texture [Maltman, 1978]) alternate with veins that contain grains $(<100 \mu \mathrm{m})$ oriented perpendicular to the foliation (Figure 1a). Zones with smaller $(<50 \mu \mathrm{m})$, randomly oriented grains are sometimes present at the center of veins (Figure 1a). The grains within the bladed zones and veins are primarily oriented parallel
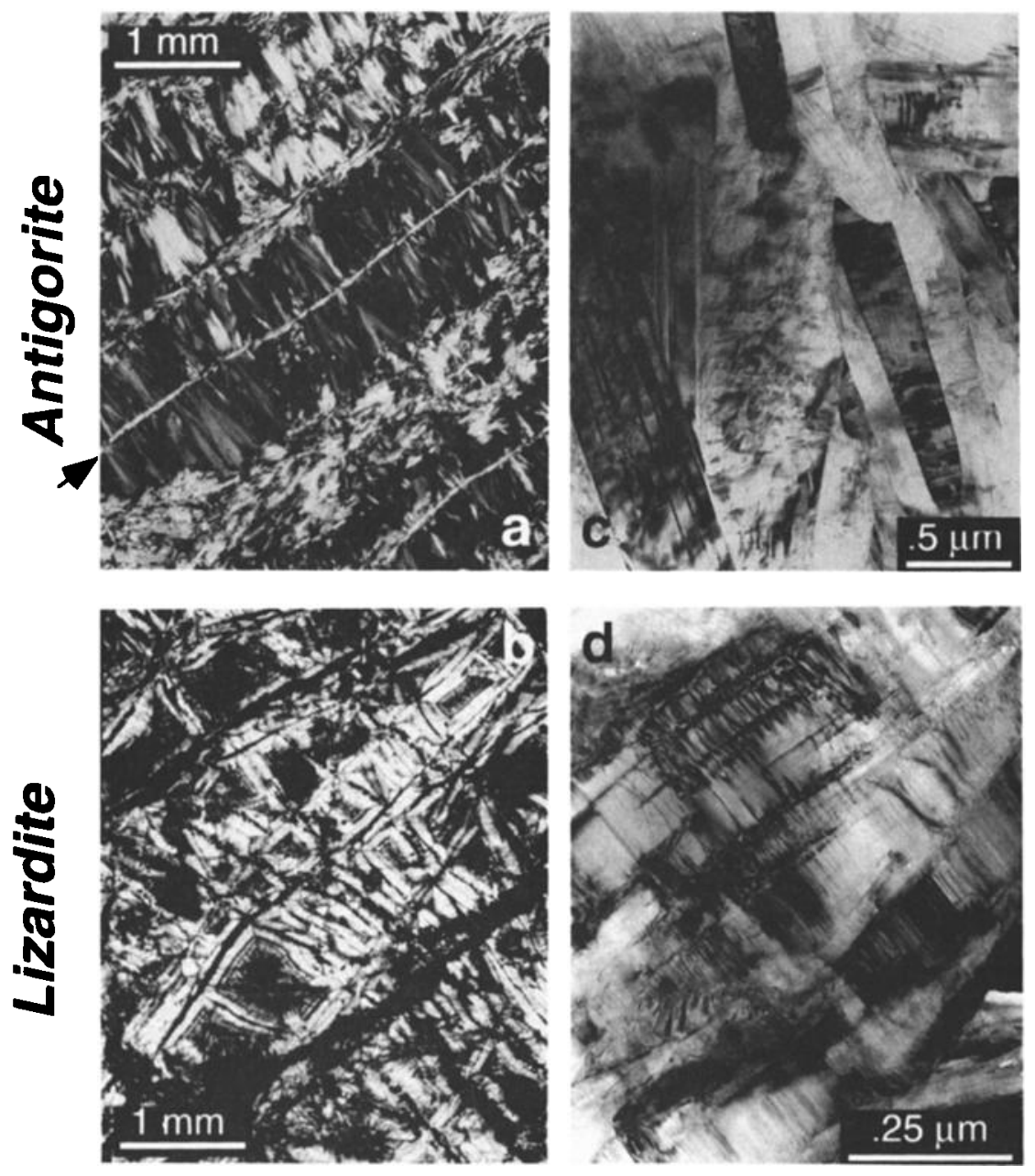

Figure 1. Optical (crossed Nicols) and TEM micrographs (bright field) of undeformed (top) antigorite and (bottom) lizardite. The foliation in antigorite (marked by arrows in Figure la) is defined by bands of grains oriented parallel and perpendicular (bladed bands and veins, respectively) to the overall foliation. Lizardite is characterized by a mesh texture that surrounds zones of micritic material (Figure 1c). The TEM micrographs of both serpentine polytypes show elongated grains, closed grain boundaries, no preexisting open microcracks, and a high density of crystal defects (Figures $1 \mathrm{~b}$ and 1d). 

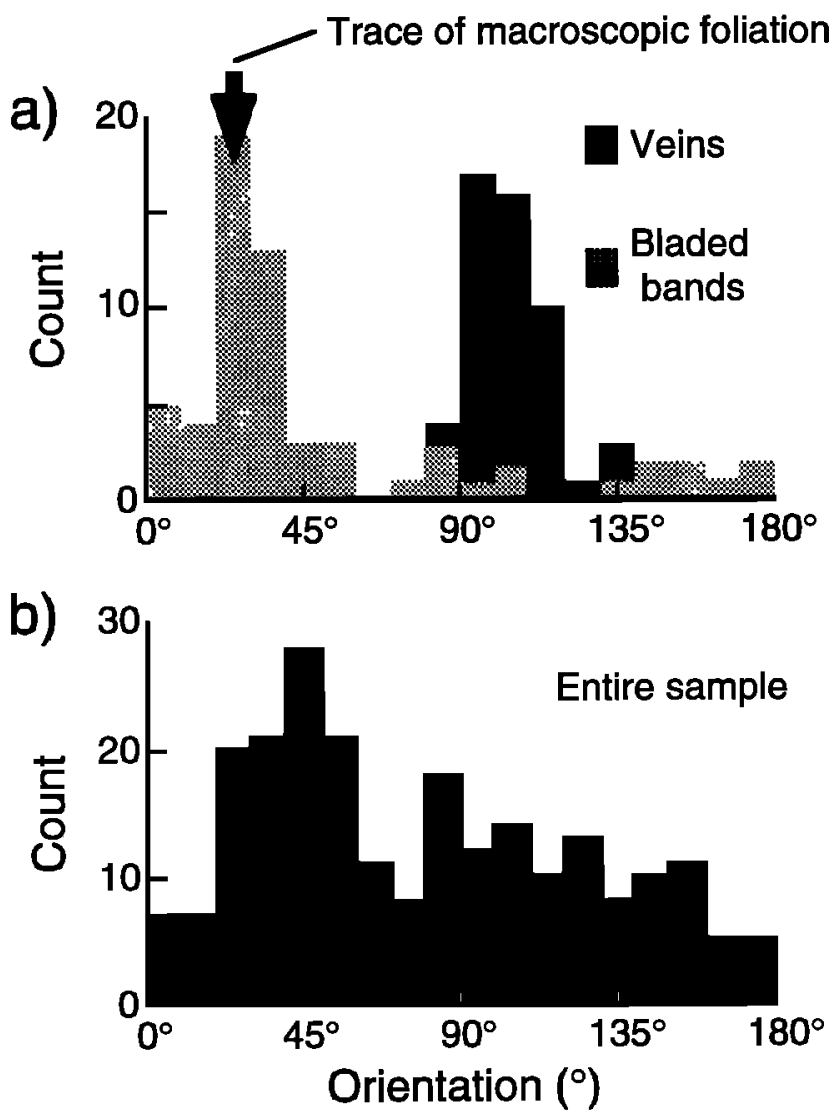

Figure 2. Lattice preferred orientation data for antigorite. (a) Histogram of the orientation of the trace of (001) from both the bladed bands (number of measurements $n=65$ ) and the veins $(n=48)$ from a plane perpendicular to the foliation. The trace of the macroscopic foliation is shown by the black arrow. (b) A histogram of mineral orientations for the entire sample $(n=129)$ shows that the mineral fabric on the whole is relatively weak. The $0^{\circ}$ orientation is arbitrary.

and perpendicular to the macroscopic foliation, respectively (Figure 2a). However, the lattice preferred orientation (LPO) of the entire sample is weak (Figure 2b). Scanning and transmission electron microscopy (SEM and TEM, respectively) show little pre-existing porosity, few open microcracks, and a large number of crystal defects (twins and dislocations, Figure $1 \mathrm{~b}$ ). The density of this material $\left(2690 \mathrm{~kg} / \mathrm{m}^{3}\right)$ is slightly higher than that of pure antigorite (of $2600 \mathrm{~kg} / \mathrm{m}^{3}$ ) [Deer et al., 1966]. Assuming that the excess density is due to the presence of iron oxides (density 5000 $\mathrm{kg} / \mathrm{m}^{3}$ ), the oxides would comprise $3.4 \%$ of the sample volume, consistent with the modal abundance estimated from thin sections.

Lizardite serpentinite. Lizardite samples were cored from serpentinized oceanic peridotites dredged along the central MidAtlantic Ridge (samples AII60 9-10, AII60 9-75, and AII60-5 from the Woods Hole Oceanographic collection) and one of unknown origin (X). All of these rocks are comprised of $>80 \%$ lizardite, minor amounts of chrysotile, and $<10 \%$ magnetite and chlorite, as indicated by powder $\mathrm{X}$ ray diffraction patterns, optical microscopy, and TEM observations; traces of olivine, enstatite, and other $\mathrm{Fe}$ oxides are also found. The microstructure of the lizardite serpentinites is more complex than that of antigorite serpentinites. Lizardite serpentinites have a "mesh texture" matrix [Wicks et al., 1977; see $O^{\prime}$ Hanley, 1996, and references therein] surrounding lizardite pseudomorphs of pyroxenes called bastites [Wicks and Whittaker, 1977; Dungan 1979], "amorphous" areas (grains $<0.01 \mu \mathrm{m}$ long), and zones with magnetite and other opaque minerals (Figure 1c). The lizardite grains within the mesh-textured zones are $<20 \mu \mathrm{m}$ long. The grain size of lizardite is too small to determine the LPO using optical microscopy. At the TEM scale, the mesh-textured regions show no preexisting porosity or open microcracks and a high density of crystal defects (dislocations and uncharacterized planar defects, Figure 1d). A small amount of porosity ( $<5 \%$ ) is present in some of the amorphous zones. As these zones comprise $<10 \%$ of the sample volume, we estimate that the porosity of the samples is $<0.5 \%$. The density of the lizardite serpentinite ( 2660 $\left.\mathrm{kg} / \mathrm{m}^{3}\right)$ is higher than that of pure lizardite $\left(2550 \mathrm{~kg} / \mathrm{m}^{3}\right)$, requiring $\sim 4.5 \%$ vol of iron oxides to account for the excess mass.

Westerly granite. Westerly granite was used to compare our volumetric strain measurements with data obtained previously using the same techniques [e.g., Brace et al., 1965]. The characteristics of the particular block of Westerly granite we used are described elsewhere [e.g., Brace, 1965; Wong, 1982].

\section{Methods}

Gas confining medium apparatus. Experiments at confining pressures $\left(P_{c}\right)$ less than $400 \mathrm{MPa}$ were conducted using argon as a confining medium. Cylindrical samples $15.88 \mathrm{~mm}$ in diameter and $25.4 \pm 2.5 \mathrm{~mm}$ in length were jacketed in copper foil and sealed with copper end caps. The samples were then pressurized to $100 \mathrm{MPa}$, and then returned to ambient conditions, to seat the jacket and to ensure a gas-tight seal. All experiments were conducted at room temperature, and at displacement rates that correspond to strain rates from $\sim 3.5 \times 10^{-4}$ to $\sim 3.8 \times 10^{-6} \mathrm{~s}^{-1}$ in average, at a constant confining pressure. The load and displacement were externally measured and digitally recorded; the load is accurate to $0.3 \mathrm{MPa}$. Two electrical strain gauges were mounted onto the collapsed copper jacket to measure axial and radial strain. Volumetric strain was calculated using the relationship: $\varepsilon_{v}=\varepsilon_{a}+2 \times \varepsilon_{r}$, where $\varepsilon_{v}, \varepsilon_{a}$, and $\varepsilon_{r}$ are the volumetric, axial, and radial engineering strain, respectively (these and other symbols are summarized in the notation section). The calculated volumetric strain is accurate at strains $<5 \%$ and/or prior to the localization of deformation on a discrete fault [e.g., Brace et al., 1966; Brace, 1978]; strain gauge measurements are precise to strains of $0.001 \%$ and accurate to $\sim 0.02 \%$ due to electronic noise. The small initial porosity (and therefore small permeability) of both serpentine rocks makes measurement of volume changes by variations in pore volume impractical [e.g., Brace, 1978].

Solid confining medium apparatus. Higher-pressure experiments $\left(P_{c}>300 \mathrm{MPa}\right)$ were conducted in a modified Griggs-type apparatus using lead as the confining medium. The runs were conducted at room temperature, confining pressures from 300 to $1000 \mathrm{MPa}$, and constant displacement rates corresponding to strain rates of $\sim 1.5 \times 10^{-5}$ and $\sim 1.5 \times 10^{-6} \mathrm{~s}^{-1}$ in average. Axial load and displacement were measured externally; the load is accurate to $\sim 50 \mathrm{MPa}$. Differential stress versus axial strain curves were calculated assuming that the samples deformed homogeneously and that the volume remained constant. Cylindrical cores (6.3 $\mathrm{mm}$ in diameter, 10 to $14 \mathrm{~mm}$ long) were jacketed in a 0.25 -mm-thick silver tube.

Sample preparation. Samples were cored from as-received 
materials and ground to obtain flat ends and parallel sides. Samples of antigorite were cored at approximately $0^{\circ}, 30^{\circ}, 45^{\circ}$, $60^{\circ}$, and $90^{\circ}$ to the weak foliation to investigate the effects of textural anisotropy.

\section{Results of Deformation Experiments}

The results of deformation experiments on antigorite, lizardite, and Westerly granite are summarized in Tables 1 and 2.

\section{Stress Versus Strain Curves}

Stress-strain curves for antigorite illustrate a transition from unstable faulting or strain weakening to flow at a constant stress with increasing pressure (Figures $3 \mathrm{a}$ and $3 \mathrm{~b}$ ). Unstable faulting was observed at $P_{c}=60 \mathrm{MPa}$, while strain weakening was observed at $P_{c}=150$ and $195 \mathrm{MPa}$. The jackets of these samples showed that deformation localized on a single fault. At $P_{c}=325$ and $345 \mathrm{MPa}$ the flow stress was constant (after an initial strain weakening in the first case); these samples showed a transitional style of deformation with the development of an $\sim 2$-mm-wide shear zone composed of several anastomosing faults. Slight strain hardening was observed at $P_{c}=725$ and $1000 \mathrm{MPa}$; these samples deformed homogeneously.

The strength of lizardite is approximately half of that of antigorite, although the macroscopic deformation behavior of both materials is similar (Figure 3). At $P_{c}=200 \mathrm{MPa}$ the stressstrain curves show strain weakening associated with shear localization on a fault; the run at $P_{c}=50 \mathrm{MPa}$ was stopped at the

Table 1. Summary of Experimental Conditions and Results

\begin{tabular}{|c|c|c|c|c|c|c|}
\hline $\operatorname{Run}^{*}$ & $P_{c}, \mathrm{MPa}$ & $\varepsilon, \times 10^{-5} \mathrm{~s}^{-1 \dagger}$ & $\sigma_{\max }, \mathrm{MPa}$ & $\sigma_{y}, \mathrm{MPa}$ & $\alpha, \operatorname{deg}$ & Regime, Apparatus $\ddagger$ \\
\hline \multicolumn{7}{|c|}{ Antigorite (VM3) } \\
\hline$a-1$ & 200 & 34.63 & 335 & 317 & 30 & $1, g$ \\
\hline$a-2$ & 0 & 0.35 & 155 & no yield & 30 & $\mathrm{a}, \mathrm{g}$ \\
\hline$a-3$ & 200 & 3.77 & 662 & 584 & 30 & $1, \mathrm{~g}$ \\
\hline$a-4$ & 195 & 3.46 & 713 & 561 & 30 & $\mathrm{l}, \mathrm{g}$ \\
\hline$a-5$ & 200 & 3.46 & 704 & 577 & 30 & $1, \mathrm{~g}$ \\
\hline$a-6$ & 200 & 3.46 & 778 & 650 & 30 & $1, \mathrm{~g}$ \\
\hline$a-7 b$ & 200 & 3.46 & 736 & 632 & 30 & $1, \mathrm{~g}$ \\
\hline$(a-8 b)$ & 200 & 3.46 & 656 & 603 & 30 & $1, \mathrm{~g}$ \\
\hline$(a-9)$ & 60 & 3.46 & 382 & n.m. & 30 & 1,0 \\
\hline $\mathrm{a}-10 \mathrm{c}$ & 200 & 3.46 & $335^{\S}$ & 328 & 30 & $1, \mathrm{~g}$ \\
\hline$a-16 c$ & 150 & 3.46 & 670 & 563 & 30 & $\mathrm{l}, \mathrm{g}$ \\
\hline$a-17 d$ & 345 & 3.46 & 952 & 724 & 30 & $\mathrm{l}, \mathrm{g}$ \\
\hline$(a-19)$ & 205 & 3.46 & 895 & 814 & 90 & $\mathrm{l}, \mathrm{g}$ \\
\hline$(a-20)$ & 206 & 3.46 & 913 & 734 & 60 & $1, \mathrm{~g}$ \\
\hline$(a-21 d)$ & 202 & 3.46 & 786 & 684 & 45 & $\mathrm{l}, \mathrm{g}$ \\
\hline$(a-22 d)$ & 208 & 3.46 & 688 & 578 & 30 & d, s \\
\hline$a-23$ & 325 & 150 & 1038 & 799 & 30 & $\mathrm{~d}, \mathrm{~s}$ \\
\hline$a-24$ & 1000 & 1.50 & 1888 & 1341 & 30 & $\overrightarrow{d, s}$ \\
\hline$a-25$ & 725 & 1.50 & 1660 & 1112 & 30 & d, $s$ \\
\hline$a-28$ & 725 & 1.50 & 1564 & 1126 & 30 & d, s \\
\hline$a-29$ & 725 & 1.50 & 1541 & 1233 & 30 & d, s \\
\hline$(a-30)$ & 200 & 3.46 & 809 & 566 & 0 & $\overrightarrow{1, g}$ \\
\hline$a-32 c$ & 202 & 3.46 & 832 & 466 & 0 & $1, \mathrm{~g}$ \\
\hline$(a-33 c)$ & 201 & 3.46 & 838 & 687 & 0 & $1, \mathrm{~g}$ \\
\hline$a-36$ & 0 & 3.46 & 304 & n.m. & 0 & $\mathrm{a}, \mathrm{g}$ \\
\hline$(a-37 b)$ & 200 & 3.46 & 656 & 590 & 45 & $1, \mathrm{~g}$ \\
\hline$(a-38 b)$ & 200 & 3.46 & 735 & 529 & 45 & $1, \mathrm{~g}$ \\
\hline$(a-57)$ & 50 & 3.22 & 446 & 320 & 45 & $1, \mathrm{~g}$ \\
\hline \multicolumn{7}{|c|}{ Lizardite (AII60 5) } \\
\hline $1-12$ & 200 & 3.46 & 393 & 322 & none & $1, \mathrm{~g}$ \\
\hline$(1-14)$ & 200 & 3.46 & 441 & 354 & none & $1, \mathrm{~g}$ \\
\hline $1-34$ & 350 & 1.50 & 335 & 231 & none & d, $s$ \\
\hline $1-35$ & 350 & 1.50 & 356 & 174 & none & $\mathrm{d}, \mathrm{s}$ \\
\hline $1-39$ & 725 & 1.50 & 671 & 369 & none & $\mathrm{d}, \mathrm{s}$ \\
\hline $1-40$ & 725 & 1.50 & 701 & 477 & none & $\mathrm{d}, \mathrm{s}$ \\
\hline$|-4|$ & 950 & 1.50 & 1141 & 571 & none & d, s \\
\hline $1-42$ & 199 & 3.17 & 368 & 217 & none & $1, g$ \\
\hline $1-43$ & 50 & 3.34 & 252 & 186 & none & $\mathrm{l}, \mathrm{g}$ \\
\hline$(1-44)$ & 128 & 3.29 & 326 & 176 & none & $1, \mathrm{~g}$ \\
\hline $1-45$ & 306 & 3.30 & 398 & 247 & none & $1, \mathrm{~g}$ \\
\hline $1-50$ & 0 & 3.46 & 50 & n.m. & none & $\mathrm{a}, \mathrm{g}$ \\
\hline \multicolumn{7}{|c|}{ Ltzardite (AII60 9-10) } \\
\hline$(1-46)$ & 200 & 3.13 & 413 & 211 & none & $\mathrm{l}, \mathrm{g}$ \\
\hline$(1-47)$ & 201 & 3.21 & 375 & 334 & none & $\mathrm{l}, \mathrm{g}$ \\
\hline $1-51$ & 300 & 1.50 & 491 & 339 & none & $\mathrm{d}, \mathrm{s}$ \\
\hline $1-52$ & 700 & 1.50 & 712 & 491 & none & $\mathrm{d}, \mathrm{s}$ \\
\hline $1-53$ & 840 & 1.50 & 871 & 462 & none & d, s \\
\hline$(1-55 d)$ & 200 & 3.16 & 406 & 367 & none & d, g \\
\hline
\end{tabular}


Table 1. (continued)

\begin{tabular}{|c|c|c|c|c|c|c|}
\hline $\operatorname{Run}^{*}$ & $P_{c}, \mathrm{MPa}$ & $\varepsilon, \times 10^{-5} \mathrm{~s}^{-1 \dagger}$ & $\sigma_{\max }, \mathrm{MPa}$ & $\sigma_{y}, \mathrm{MPa}$ & $\alpha, \operatorname{deg}$ & Regime, Apparatus ${ }^{\ddagger}$ \\
\hline \multicolumn{7}{|c|}{ Lizardite (AII60 9-75) } \\
\hline $\begin{array}{c}(1-48) \\
(1-49) \\
(1-54 d) \\
(1-58) \\
(1-59) \\
1-60 \\
1-61\end{array}$ & $\begin{array}{r}200 \\
201 \\
200 \\
50 \\
100 \\
5 \\
400\end{array}$ & $\begin{array}{l}3.18 \\
3.31 \\
3.26 \\
3.22 \\
3.22 \\
3.26 \\
3.25\end{array}$ & $\begin{array}{l}432 \\
365 \\
427 \\
278 \\
291 \\
137 \\
537\end{array}$ & $\begin{array}{l}302 \\
241 \\
324 \\
245 \\
230 \\
\text { n.m. } \\
270\end{array}$ & $\begin{array}{c}\text { none } \\
\text { none } \\
\text { none } \\
\text { none } \\
\text { none } \\
\text { none } \\
\text { none }\end{array}$ & $\begin{array}{l}\mathrm{l}, \mathrm{g} \\
\mathrm{l}, \mathrm{g} \\
\mathrm{l}, \mathrm{g} \\
\mathrm{l}, \mathrm{g} \\
\mathrm{l}, \mathrm{g} \\
\mathrm{l}, \mathrm{g} \\
\mathrm{d}, \mathrm{g}\end{array}$ \\
\hline \multicolumn{7}{|c|}{ Lizardite $(X)$} \\
\hline $\mathrm{I}-31 \mathrm{~b}$ & 200 & 3.46 & 441 & 384 & none & $\mathrm{l}, \mathrm{g}$ \\
\hline \multicolumn{7}{|c|}{ Westerly Grante } \\
\hline $\begin{array}{c}(\mathrm{g}-18) \\
\mathrm{g}-26 \\
(\mathrm{~g}-27)\end{array}$ & $\begin{array}{r}200 \\
0 \\
200\end{array}$ & $\begin{array}{l}3.46 \\
3.46 \\
3.46\end{array}$ & $\begin{array}{r}1096 \\
124 \\
1008\end{array}$ & $\begin{array}{l}638 \\
\text { n.m. } \\
655\end{array}$ & $\begin{array}{l}\text { none } \\
\text { none } \\
\text { none }\end{array}$ & $\begin{array}{l}\mathrm{l}, \mathrm{g} \\
\mathrm{a}, \mathrm{g} \\
\mathrm{l}, \mathrm{g}\end{array}$ \\
\hline
\end{tabular}

\footnotetext{
Abbreviation n.m., not measured.

* Runs for which volumetric data are available (Table 2) are indicated in parenthesis.

$\dagger$ The bulk of the experiments were conducted at $\varepsilon \sim 10^{-5} \mathrm{~s}^{-1}$.

${ }^{\ddagger}$ Deformation regime: a, axial splitting; l, localized deformation; d, distributed deformation. Apparatus: g, gas confining medium; $\mathrm{s}$, solid confining medium.

$\$_{\text {Run }} 10 \mathrm{c}$ faulted after yielding but prior to attaining the maximum stress.
}

peak stress, prior to strain localization (Figure 3c). Steady state flow or slight strain hardening was observed at $P_{c} \geq 300 \mathrm{MPa}$ (Figures 3c and 3d). Similar to our observations for antigorite, the jackets of samples deformed at 300 and $400 \mathrm{MPa}$ revealed a

Table 2. Volumetric Strain Data

\begin{tabular}{|c|c|c|c|}
\hline Run & $P_{c}, \mathrm{MPa}$ & $c^{1 / \sigma_{\max }}$ & $\Delta \varepsilon_{v}, \%$ \\
\hline \multicolumn{4}{|c|}{ Antigorite } \\
\hline$a-8 b$ & 200 & 0.83 & -0.04 \\
\hline$a-9$ & 60 & 0.89 & -0.10 \\
\hline$a-19$ & 205 & 0.89 & -0.07 \\
\hline$a-20$ & 206 & 1.00 & 0.00 \\
\hline$a-21 d$ & 202 & 0.75 & 0.15 \\
\hline$a-22 d$ & 208 & 0.93 & -0.05 \\
\hline$a-30$ & 200 & 0.58 & 0.15 \\
\hline$a-33 c$ & 201 & 0.95 & -0.04 \\
\hline$a-37 b$ & 200 & 0.91 & 0.03 \\
\hline$a-38 b$ & 200 & 0.79 & -0.18 \\
\hline$a-57$ & 50 & 087 & -0.02 \\
\hline \multicolumn{4}{|c|}{ Lizardite } \\
\hline $1-14$ & 200 & 093 & -0.04 \\
\hline $1-31$ & 200 & 0.91 & 0.14 \\
\hline $1-46$ & 200 & not measured & -0.10 \\
\hline $1-47$ & 201 & 0.91 & -0.10 \\
\hline $1-48$ & 200 & 093 & -0.10 \\
\hline 1.49 & 201 & 0.71 & -0.20 \\
\hline $1-54$ & 200 & 0.94 & 0.10 \\
\hline $1-55$ & 200 & 1.00 & 0.00 \\
\hline $1-58$ & 50 & 088 & -0.03 \\
\hline $1-59$ & 100 & 0.89 & -0.20 \\
\hline \multicolumn{4}{|c|}{ Westerly grante } \\
\hline g-18 & 200 & 038 & 0.80 \\
\hline g-27 & 200 & 0.44 & 035 \\
\hline
\end{tabular}

* Difference between measured and extrapolated elastic volumetric strain at failure transitional style of deformation, while those of samples deformed at 700,840 , and $950 \mathrm{MPa}$ showed no evidence for strain localization.

The elastic portion of the stress-strain curves (i.e., Young's modulus) is similar for experiments on antigorite conducted in both the gas and the solid medium apparatus (Figures $3 a$ and $3 b$ ). In contrast, the Young's modulus of lizardite displays some variability; in Figure $3 \mathrm{~d}$ the differential stress at $2 \%$ strain varies by $\sim 200 \mathrm{MPa}$. The similarity of the Young's modulus observed for antigorite runs indicates that results from the two apparatus are comparable. Cyclic loading experiments on lizardite demonstrate that deformation in the preyield portion of the stressstrain curves is elastic. Results from a cyclic loading experiment are shown in Figure 3c. In run 1-54 the sample was successively loaded at $P_{c}=200 \mathrm{MPa}$ to differential stresses of 51, 82, 305 and $424 \mathrm{MPa}$; permanent strain was only observed after the sample was loaded to $305 \mathrm{MPa}$, past the yield point (i.e., deviation from an approximately linear loading curve).

\section{Pressure Dependence}

In both serpentine polytypes, the yield stress $\left(\sigma_{y}\right)$ and the maximum differential stress $\left(\sigma_{\max }\right)$ depend positively on pressure, but the pressure dependence is somewhat lower for lizardite than for antigorite (Figure 4). At a given pressure, the strength of antigorite $\sigma_{\max }$ varies by $\sim 250 \mathrm{MPa}$, while that of lizardite varies by $\sim 150 \mathrm{MPa}$ (Figure $4 \mathrm{~b}$ ). Part of the scatter in the strength of antigorite can be attributed to mechanical anisotropy. As shown in Figure 5, the strength of antigorite depends on the angle between the macroscopic foliation and the shortening direction; for any given orientation the strength of antigorite varies by $\sim 150 \mathrm{MPa}$.

The strength and the pressure dependence of strength are lower for both serpentinites (but most notably for lizardite) than for other rocks deformed in the brittle regime. This observation is illustrated by the Mohr envelopes shown in Figure 6a. These envelopes were calculated using the data listed in Table 1, data 

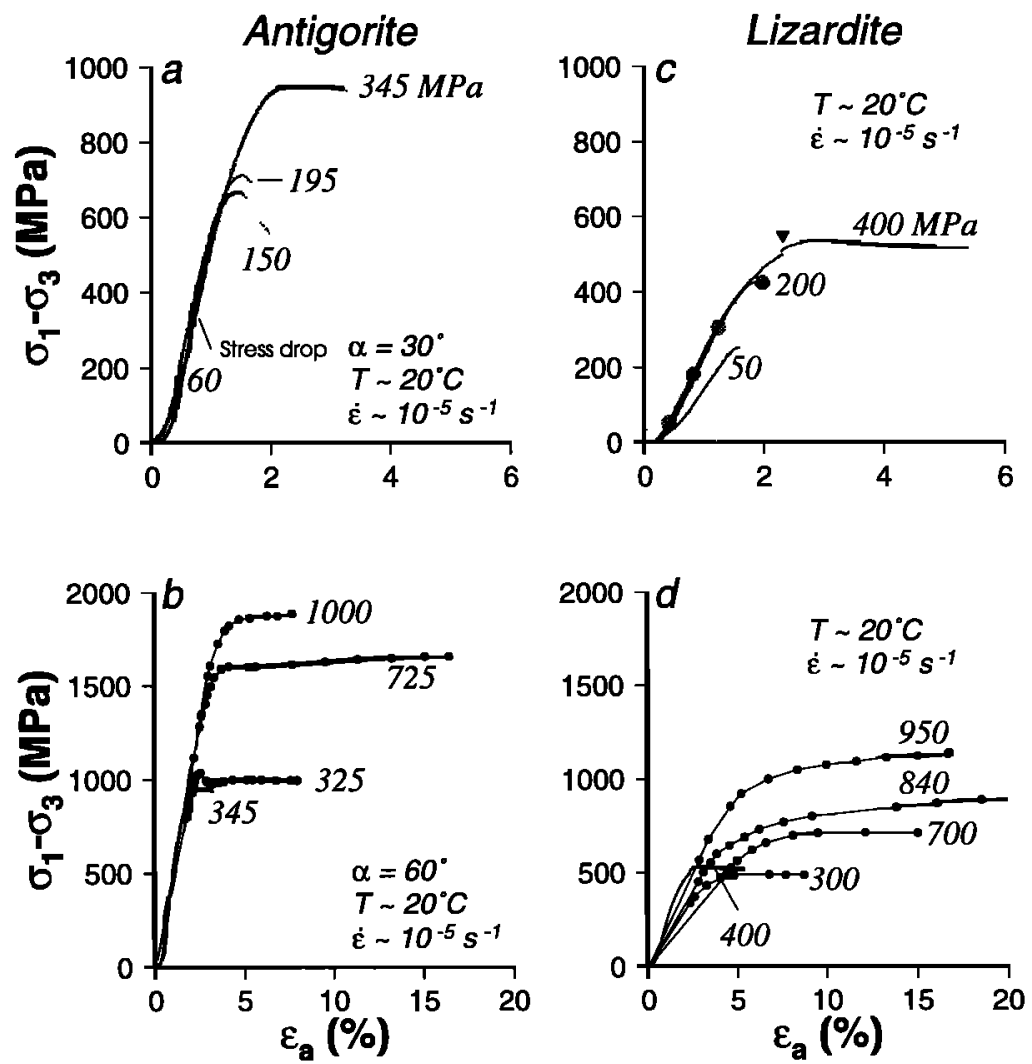

Figure 3. Differential stress $\left(\sigma_{1}-\sigma_{3}\right)$ versus axial strain $\left(\varepsilon_{a}\right)$ curves for (left) antigorite and (right) lizardite as a function of pressure. Figures $3 \mathrm{a}$ and $3 \mathrm{c}$ correspond to runs conducted in the gas rig at $P_{c}<400 \mathrm{MPa}$. Figures $3 \mathrm{~b}$ and 3d correspond to runs conducted in the solid-medium rig at $P_{c}>300 \mathrm{MPa}$; a run from the gas rig has also been plotted in both figures $3 \mathrm{~b}$ and $3 \mathrm{~d}$ for comparison (at $P_{c}=345$ and $P_{c}=400 \mathrm{MPa}$, respectively). Both antigorite and lizardite show a positive pressure dependence of the maximum stress. The elastic modulus of antigorite measured from runs in the solid- and gas-confining medium apparatus are the same. The variability in the elastic properties of lizardite is larger than for antigorite, even among runs conducted in the same apparatus. The run at $60 \mathrm{MPa}$ in Figure 3a showed a sudden drop (faulting). The triangle in Figure 3c indicates where confining pressure was increased slightly to maintain $P_{c} \sim 400 \mathrm{MPa}$. Curves are shown for runs a-24 (1000 MPa), a-25 (725 MPa), a-23 (325 MPa), a-17d (345 MPa), a-4c (195 MPa), a-16c (150 MPa), and a-09 (60 MPa) for antigorite, and from runs l41 (950), l-53 (840 MPa), l-52 (700 MPa), l-61 (400 MPa), l-51 (300 MPa), l-54 (200 MPa), and l-43 (50 MPa) for lizardite; $\boldsymbol{\alpha}$ is the angle between the shortening direction and the foliation (see notation section).

for Westerly granite from Brace et al. [1965], and data for dunite from Shimada et al. [1983]. All of the experiments were conducted at strain rates between $10^{-6}$ and $10^{-5} \mathrm{~s}^{-1}$. As the strain rate dependence of the maximum stress in the brittle regime is small [e.g., Sano et al., 1981], the failure envelopes for each rock type can be compared directly. The lower strength of serpentinites can be attributed partly to their lower pressure dependence of strength. However, at high pressures the coefficients of internal friction $\left(\mu_{t}\right)$ of lizardite, antigorite, and granite are similar $\left(\mu_{i} \sim 0.35-0.45\right)$. Thus the differences in strength at normal stresses $\left(\sigma_{n}\right)$ greater than $1000 \mathrm{MPa}$ must be attributed to other properties of these rocks (e.g., cohesive strength).

The differences in strength and the pressure dependence of strength shown by the Mohr envelopes in Figure 6a may also be correlated with observations made during frictional sliding experiments on serpentinite at lower pressures [e.g., Dengo and Logan, 1981; Reinen et al., 1994; Moore et al., 1995]. While the coefficient of friction $(\mu)$ for antigorite is somewhat lower than the value of $\mu \sim 0.85$ predicted by "Byerlee's law" [Byerlee, 1978] at $\sigma_{n}<200 \mathrm{MPa}$, lizardite is substantially weaker than either antigorite or rocks that follow Byerlee's law (Figure 6b).

\section{Volumetric Strain}

Most crystalline rocks that undergo brittle deformation exhibit significant dilation associated with the opening of axial microcracks [e.g., Brace et al., 1966; Paterson, 1978]. However, volumetric strain data indicate that brittle deformation of serpentinites is mostly nondilatant. Strain gauges were only used on samples deformed in the gas apparatus (13 runs on antigorite, 12 runs on lizardite, and 2 runs on granite, Table 2). Minor amounts of dilatancy $\left(<0.15 \% \Delta \varepsilon_{v}\right)$ were only observed during 3 of 13 experiments on antigorite and 2 of 12 experiments on lizardite. In all other cases deformation resulted in either minor amounts of apparent compaction $\left(<0.2 \% \Delta \varepsilon_{v}\right)$ or no resolvable permanent volume change (Table 2 ).

Both polytypes show a range of mechanical behavior involving small amounts of apparent dilation, compaction, or no 

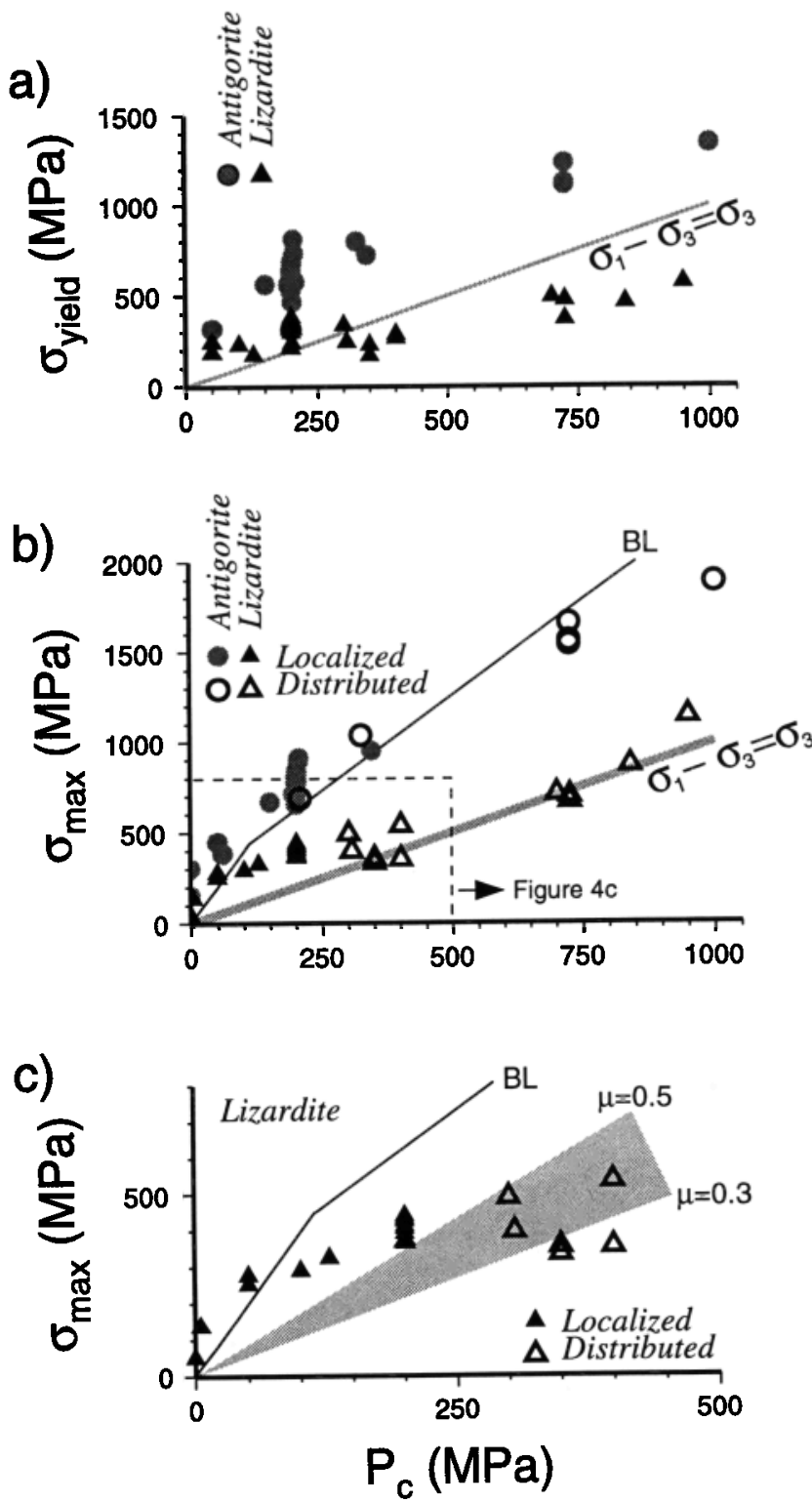

Figure 4. (a) The yield stress $\sigma_{y}$ and (b) maximum stress $\sigma_{\max }$ in both antigorite and lizardite show positive pressure dependence for $P_{c}$ up to $1 \mathrm{GPa}$. Lizardite is approximately a factor of 2 weaker than antigorite and shows a smaller pressure dependence of strength. The gray line in Figures $4 a$ and $4 b$ corresponds to Goetze's criterion $\left(\sigma_{1}-\sigma_{3}=\sigma_{3}\right)$. (c) The transition from localized to distributed deformation is often observed when the strength of a material becomes less than Byerlee's friction law. However, the results in lizardite indicate that this criterion should incorporate the friction law derived for each rock type instead of Byerlee's law (line labeled BL in Figures $4 \mathrm{~b}$ and $4 \mathrm{c}$ ). Upper and lower limits of the friction law of lizardite correspond to $\mu=0.3$ [Reinen et al., 1994] and $\mu=0.5$ [Dengo and Logan, 1981] for lizardite serpentine gouges and bare surfaces, respectively.

permanent volume change (Figure 7). For antigorite, three examples are shown in Figure 7a, one that resulted in dilation, another in compaction (both at $P_{c}=200 \mathrm{MPa}$ ) and a third that showed no resolvable permanent volume change $\left(P_{c}=50 \mathrm{MPa}\right)$. Lizardite exhibits similar variability in volumetric strain behavior

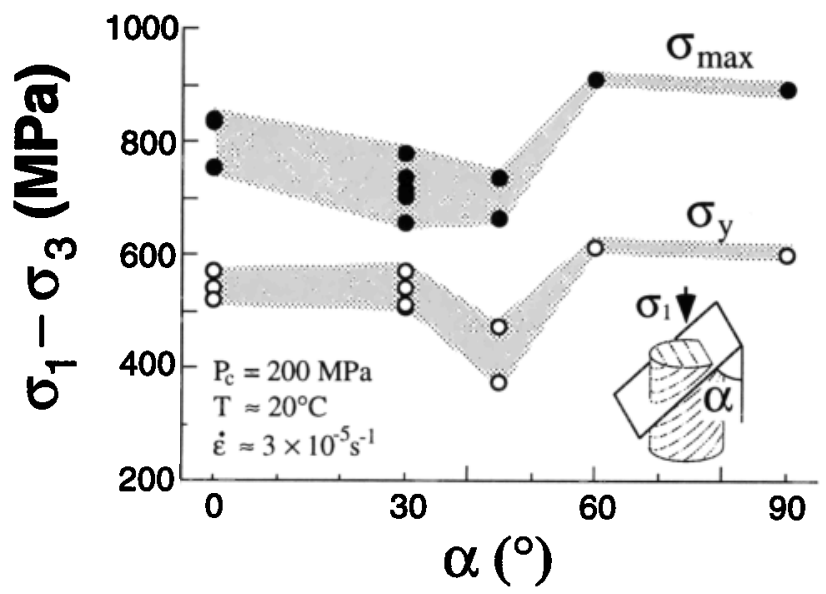

Figure 5. Mechanical anisotropy resulting from the macroscopic foliation in antigorite. Both the peak $\left(\sigma_{\max }\right.$, denoted as solid circles) and yield stress ( $\sigma_{y}$, open circles) depend on the inclination of the foliation (see inset). Both $\sigma_{\max }$ and $\sigma_{y}$ are lowest at $\alpha \approx 45$. The variability in strength at any given orientation is $\sim 150 \mathrm{MPa}$.
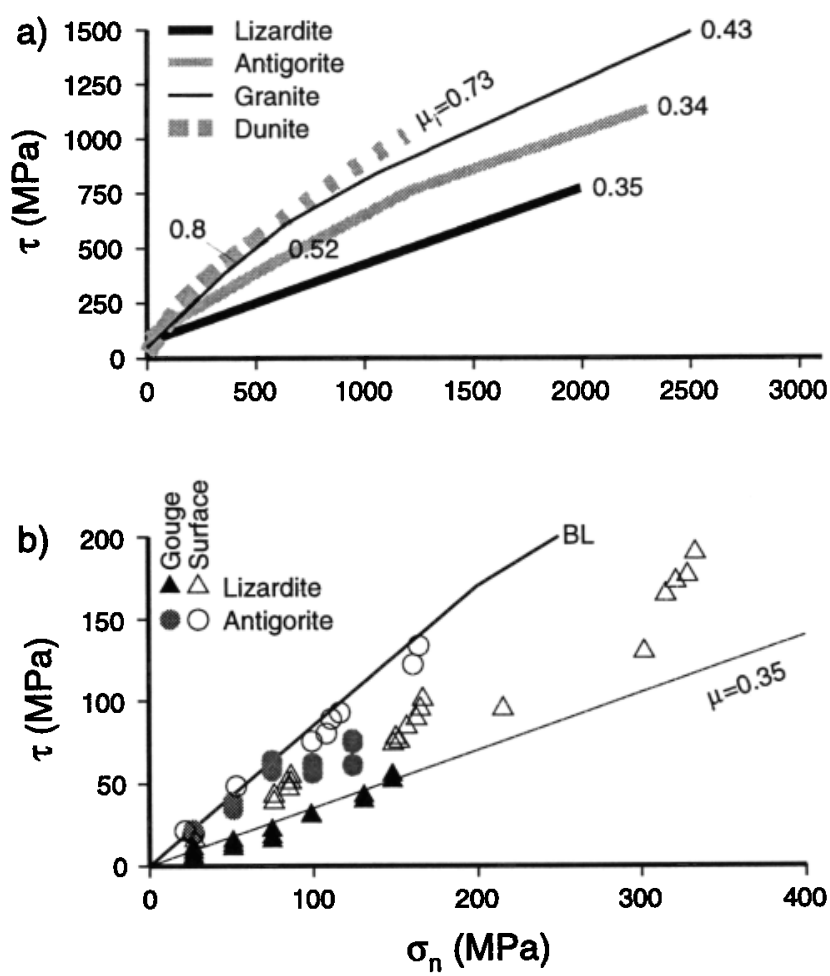

Figure 6. (a) Mohr envelopes and (b) friction data for lizardite and antigorite deformed at room temperature. Figure $6 \mathrm{a}$ shows a comparison of Mohr envelopes for antigorite and lizardite serpentinite compared to Mohr envelopes derived from data on granite [Brace et al., 1966] and dunite [Shimada et al., 1983]. The coefficient of internal friction $\mu_{l}$ is given by the slope of the Mohr envelope. Figure $6 \mathrm{~b}$ shows friction data from experiments on bare polished surfaces (open symbols [Dengo and Logan, 1981]) and fault gouge (solid symbols [Reinen et al., 1994]) of antigorite and lizardite serpentinites. For comparison, Byerlee's law (BL) and a friction law for serpentinite with $\mu=0.35$, corresponding to the coefficient of internal friction shown in Figure 6a, are also plotted. 


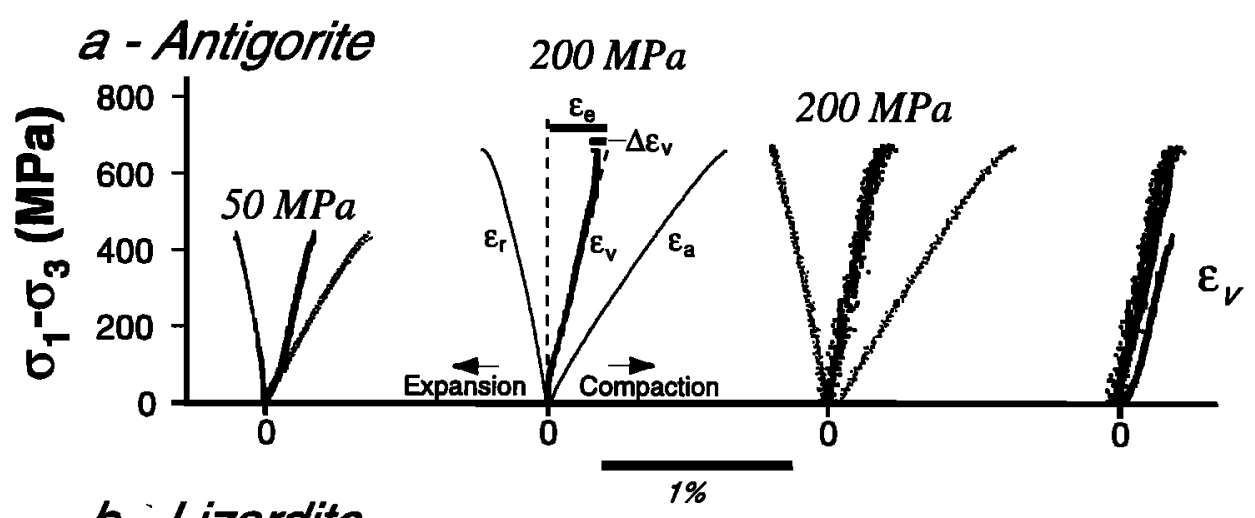

$b$ - Lizardite
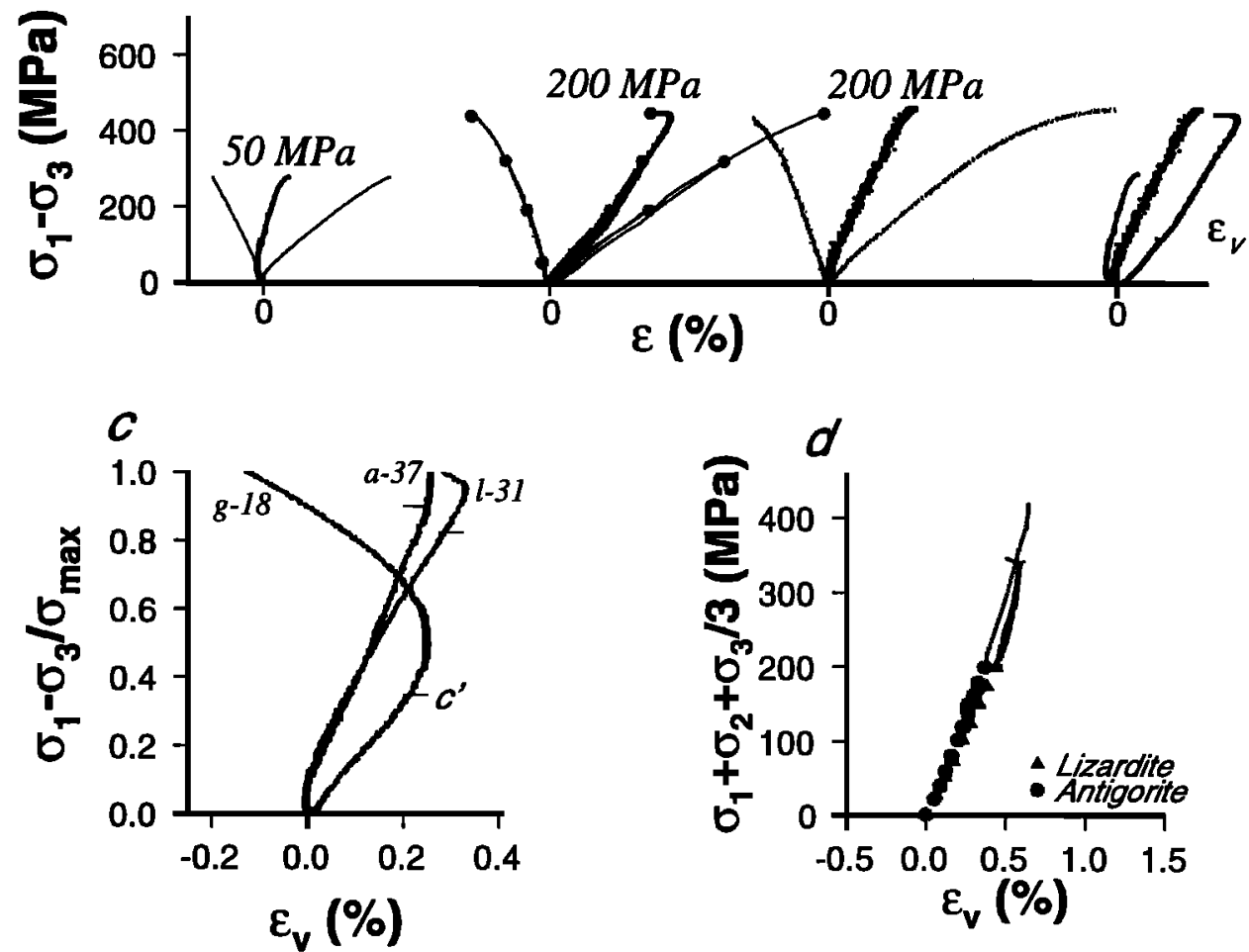

Figure 7. Stress versus volumetric strain curves. (a) Curves for experiments on antigorite. The finer connected dots correspond to axial ( $\varepsilon_{a}$, positive) and radial strains ( $\varepsilon_{r}$, negative), and the bold dots are the calculated volumetric strains $\left(\varepsilon_{v}=\varepsilon_{a}+2 \times \varepsilon_{r}\right)$. The deviation from the linear trend of $\varepsilon_{v}$ corresponds to the onset of dilatancy or compaction ( $c$ ). The magnitude of dilatancy or compaction $\left(\Delta \varepsilon_{v}\right)$ is the difference between the observed volumetric strain and the elastic strain $\varepsilon_{e}$ extrapolated along a line to $\sigma_{\max }$. To facilitate comparison, individual curves are displaced laterally, and the calculated volumetric strain curves are plotted together on the right. The variability in the width of the curves is due to electronic noise. Although all experiments resulted in localized brittle deformation, little or no dilatancy was observed prior to failure. Curves are shown for runs a-57 (50 MPa), a-22, and a-38 (200 MPa). (b) Curves for experiments on lizardite; 1-58 (50 MPa), 1-55, and 1-14 (200 MPa). The gray dots on the central curve indicate the end of successive loading and unloading cycles. (c) Comparison of $\varepsilon_{v}$ observed for lizardite and antigorite (1-31 and a-37) to $\varepsilon_{v}$ for Westerly granite (g-18) deformed at the same conditions $\left(P_{c}=200 \mathrm{MPa}, T \sim 20^{\circ} \mathrm{C}\right)$. The magnitude of volume change is significantly smaller for serpentinite. In addition, $c^{\prime}$ for serpentinite (thin lines) occurs much later in the loading history. In this figure the differential stress has been normalized by $\sigma_{\max }$ to facilitate comparison. (d) Mean stress $\left(\sigma_{\mathrm{m}}=\left[\sigma_{1}+\sigma_{2}+\sigma_{3}\right] / 3\right)$ versus $\varepsilon_{v}$ curves for experiments conducted on lizardite and antigorite at $P_{c}=200 \mathrm{MPa}$. The $\varepsilon_{v}$ up to $\sigma_{\mathrm{m}}=200 \mathrm{MPa}$ was measured during pressurization. The hydrostatic portion of the curve (large dots, $\sigma_{m}<200 \mathrm{MPa}$ ) yields a bulk modulus similar to that determined during triaxial loading (fine dots, $\sigma_{\mathrm{m}}>200 \mathrm{MPa}$ ).

(Figure 7b). Two of the examples display limited compaction $\left(P_{c}=50\right.$ and $\left.200 \mathrm{MPa}\right)$, while another for a sample deformed at $P_{c}=200 \mathrm{MPa}$ shows a small amount of dilation.

The variability in the volumetric strain behavior does not appear to correlate with sample-scale textural anisotropy (i.e., the location of strain gauges with respect to the foliation in antigorite). In the case of the lizardite samples there is no recognizable macroscopic foliation. As discussed below, a possible explanation for the variability in the volumetric strain behavior is the development of inhomogeneous strain patterns 


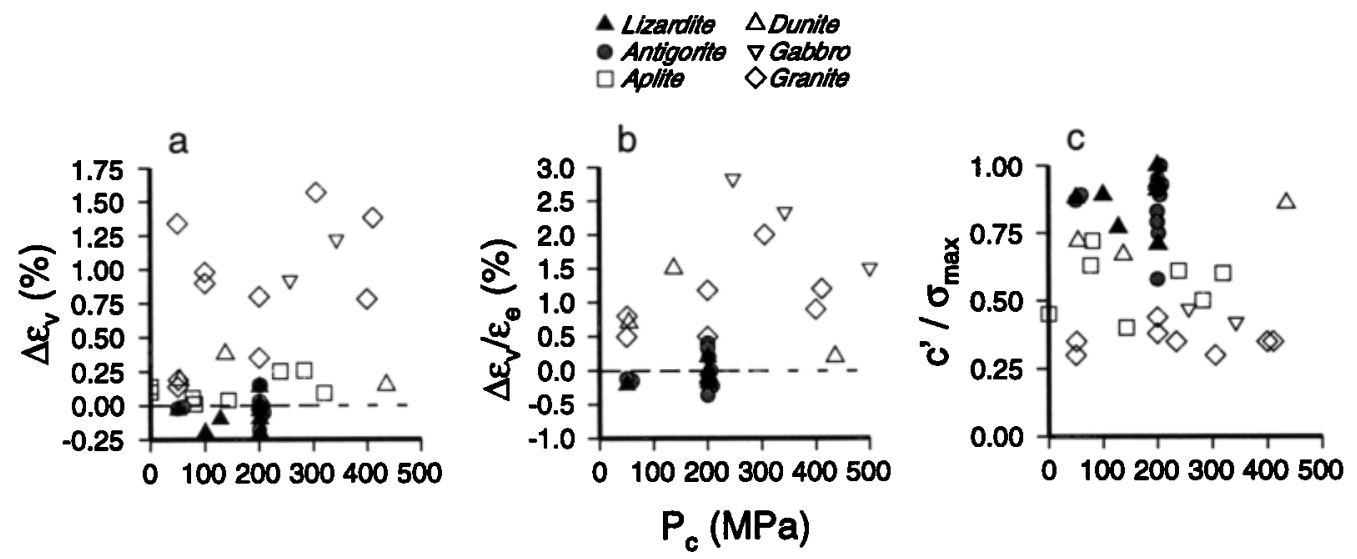

Figure 8. Volumetric strain data for serpentinite and other rocks. (a) Both serpentine polytypes display effectively nondilatant behavior $\left(\left|\Delta \varepsilon_{v}\right|<0.2 \%\right)$, while granite, dunite and gabbro show $\Delta \varepsilon_{v}$ typically $>0.2 \%$. Aplite shows the smallest amount of dilatancy $\left(0<\Delta \varepsilon_{v}<0.25 \%\right)$ of the other crystalline rocks. Data for granite and aplite are from Brace et al. [1966], dunite and gabbro are from Shimada et al. [1983]. (b) $\Delta \varepsilon_{v}$ normalized by the extrapolated elastic strain at failure $\left(\varepsilon_{v}\right)$. (c) Plot of $c^{\prime} / \sigma_{\max }$ versus $P_{c}$ showing that dilation (or apparent compaction) of antigorite initiates very close to failure for both antigorite and lizardite; dilation occurs much earlier in the loading cycle for the other rocks.

caused by fault localization under or in the immediate vicinity of strain gauges.

Even when serpentinites dilate, the volume increase is small when compared with that of granite deformed at the same conditions (Figure 7c). Note also that the deviation from elastic behavior ( $c^{\prime}$, the stress at which stress and strain are not linearly related) occurs much later during the loading cycle in both serpentinites than in granite. Values of $c^{\prime} / \sigma_{\max }$ for serpentinites range from 0.71 to 1 (Table 1 ), while those for granite range between 0.3 and 0.6 [Brace et al., 1965]. Both the lack of dilatancy and the high values of $c / \sigma_{\max }$ indicate that serpentinites define an end-member style of brittle deformation. The unique nature of the mechanical behavior of serpentinites is further appreciated when comparisons are extended to other rock types such as aplite, granite, and gabbro (Figure 8). Serpentinites are the only one of these rock types that do not show strongly dilatant volumetric strain behavior (Figure 8a). As shown in Figure 8b, the difference in volumetric strain behavior is more apparent when $\Delta \varepsilon_{v}$ is normalized by the extrapolated elastic strain $\varepsilon_{e}$ [Brace et al., 1965]. The values of $c^{\prime} / \sigma_{\max }$ for serpentinites are generally $>0.7$, while the values measured for gabbro, dunite, and aplite are always $<0.75$ and can be as low as 0.25 (Figure $8 \mathrm{c}$ ).

The volumetric strain measurements also illustrate the elastic nature of deformation prior to yielding. Plots of mean stress $\left(\sigma_{\mathrm{m}}=\left[\sigma_{1}+\sigma_{2}+\sigma_{3}\right] / 3\right)$ versus volumetric strain for both antigorite and lizardite show a coincidence of the effective bulk modulus measured during hydrostatic and subsequent triaxial loading (Figure 7d). The effective bulk modulus is given by the slope of the $\sigma_{\mathrm{m}}$ versus $\varepsilon_{v}$ curve; similar slopes are obtained during both the hydrostatic $\left(\sigma_{1}=\sigma_{3}\right)$ and triaxial $\left(\sigma_{1}>\sigma_{3}\right)$ loading (Figure $7 \mathrm{~d}$, circles versus lines), indicating that significant pore collapse did not occur during pressurization.

\section{Microstructural Observations}

As the confining pressure increases, the mode of deformation changes from localized (brittle) to distributed (ductile) deformation in both antigorite and lizardite. These observations are summarized on a plot of $\sigma_{\max }$ versus $P_{c}$ in Figure $4 \mathrm{~b}$.
Microstructural observations were made on samples deformed in both regimes to determine the processes responsible for the transition in macroscopic deformation behavior.

\section{Localized Deformation Regime}

Optical microscope observations on both serpentine polytypes indicate that deformation localizes on a single fault. In all cases the faults form at high angles $\left(30^{\circ}-45^{\circ}\right)$ to the shortening direction. Microcracking is generally restricted to the immediate vicinity of the shear zones; the microstructure at distances greater than $\sim 50 \mu \mathrm{m}$ from the fault zones is indistinguishable from that of the starting material. However, incipient shear zones of limited extent that accommodate small amounts of strain were observed throughout.

In faulted samples of lizardite and antigorite the crystallographic anisotropy of individual grains controls the formation of microcracks and the localization of strain. Faults in antigorite form within the "bladed bands," where the grains are oriented parallel to the foliation. Microcracking is crystallographically controlled, as illustrated by optical micrographs of an antigorite sample that was unloaded immediately after the onset of strain weakening (Figures 9a and 9b). Two incipient fault zones run along two "bladed bands"; in both cases the $(001)$ cleavage of the grains within the bands is parallel to the faults. A TEM micrograph of one of these incipient faults illustrates that microcracks form almost exclusively along (001) grain boundaries, although some intragranular cracks parallel to the (001) cleavage are also observed (Figure 9c). The microcracks illustrated in Figure 9c are oriented at high angles $\left(>20^{\circ}\right)$ to the shortening direction, consistent with observations at the optical microscope scale. No axial cracks are observed even at the TEM scale. Figures $9 a$ and $9 \mathrm{~b}$ also show that the "jog" connecting the two incipient faults is defined by cracks oriented along (001) grain boundaries.

Microcracks in faulted samples of lizardite also form parallel to the (001) cleavage. Fault zones tend to follow the rims of the mesh-textured regions (Figures 9d and 9e). A TEM micrograph of a fault zone in a lizardite sample deformed at the same conditions as that shown in Figure 9d is shown in Figure 9f. Both 


\section{Plane light}
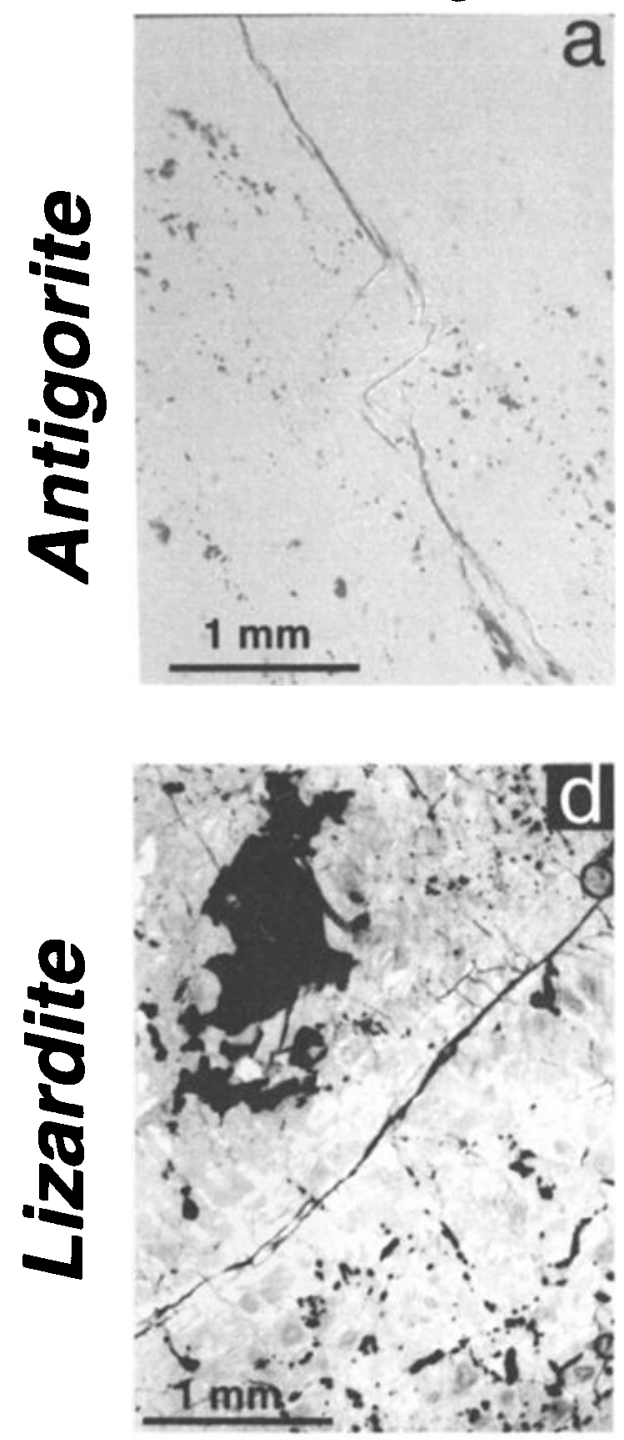

\section{Crossed Nicols}

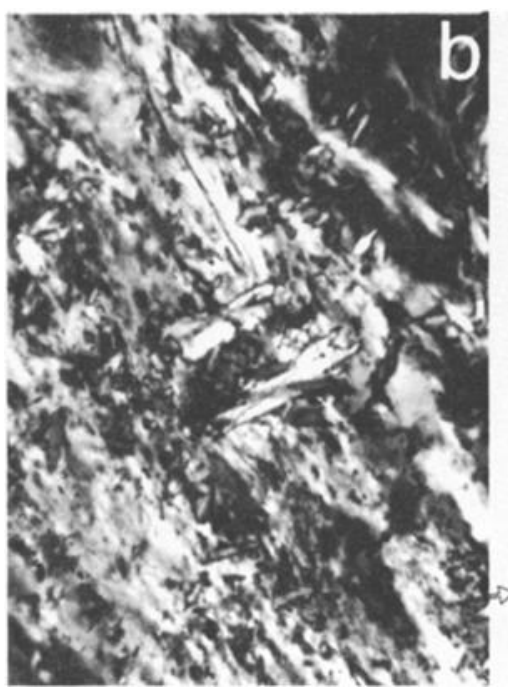

TEM

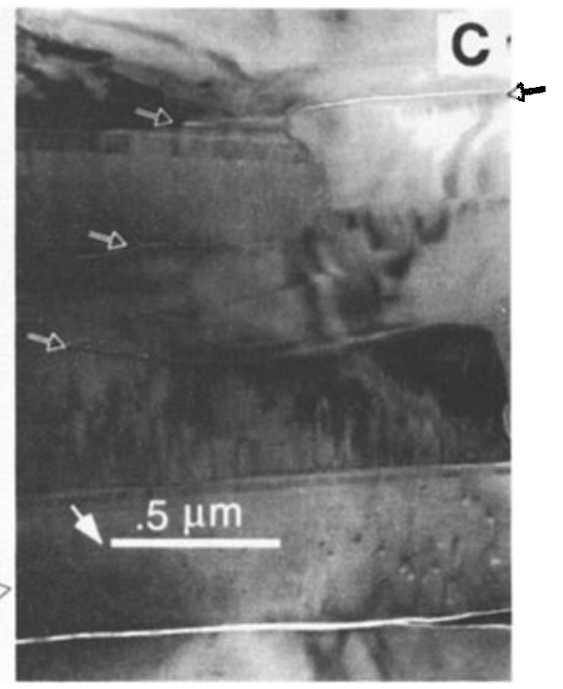

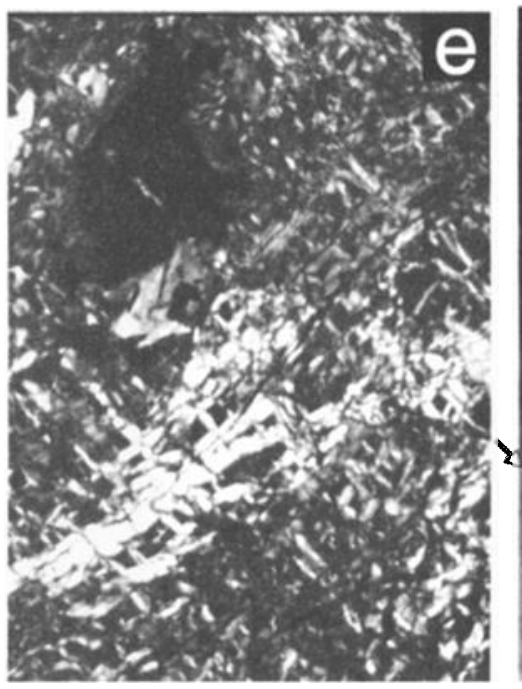

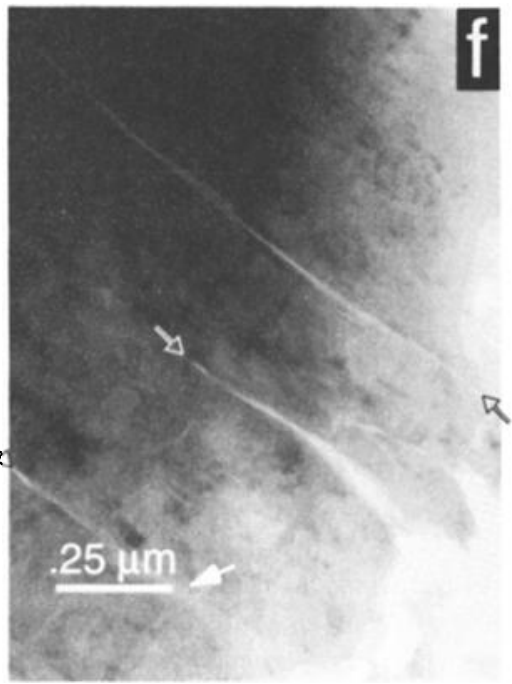

Figure 9. (a-c) Microstructures of faulted samples of antigorite and (d-f) lizardite deformed at low confining pressures. In the optical micrographs the same region is shown in both plane light and crossed Nicols. In all cases faults and microcracks follow zones of subparallel grains and/or grain boundaries; $\sigma_{1}$ (shortening direction) is vertical for all the optical micrographs. Cracks are at a high angle to $\sigma_{1}$ indicating that they are shear microcracks. TEM micrographs from areas adjacent to faults (Figures 9c and 9f) demonstrate that microcracks (open arrows) form parallel to the (001) cleavage and at high angles to the shortening direction (white arrow by scale bar). The micrographs correspond to samples a-7 (Figures 9a-9c), 1-31 (Figures 9d and 9e), and 1-49 (Figure 9f).

grain boundary and intragranular microcracks were observed parallel to the (001) cleavage. Qualitatively, intragranular microcracking is more abundant in lizardite than in antigorite.

\section{Distributed Deformation Regime}

Microstructural observations for samples of both antigorite and lizardite deformed in the distributed ("ductile") deformation regime reveal numerous shear zones of limited lateral extent (0.01-1 mm long) that accommodate small amounts of strain. These shear zones are homogeneously distributed throughout the sample, form at high angles to the shortening direction, and are oriented in conjugate directions. Micrographs of samples deformed in this regime demonstrate that the zone of microcracking associated with individual shear zones is wider than that observed in the localized regime (Figure 10). The change from localized to distributed deformation is characterized by a transitional style of deformation at $P_{c} \sim 400 \mathrm{MPa}$. In the transitional regime strain is accommodated on $\sim 1$-mm-wide fault zones that are composed of anastomosing and crosscutting shear zones.

TEM observations demonstrate that the (001) cleavage also controls microcracking in both antigorite and lizardite deformed in the distributed deformation regime. Examples of both intragranular and grain boundary microcracks oriented parallel to 


\section{Antigorite Plane light}
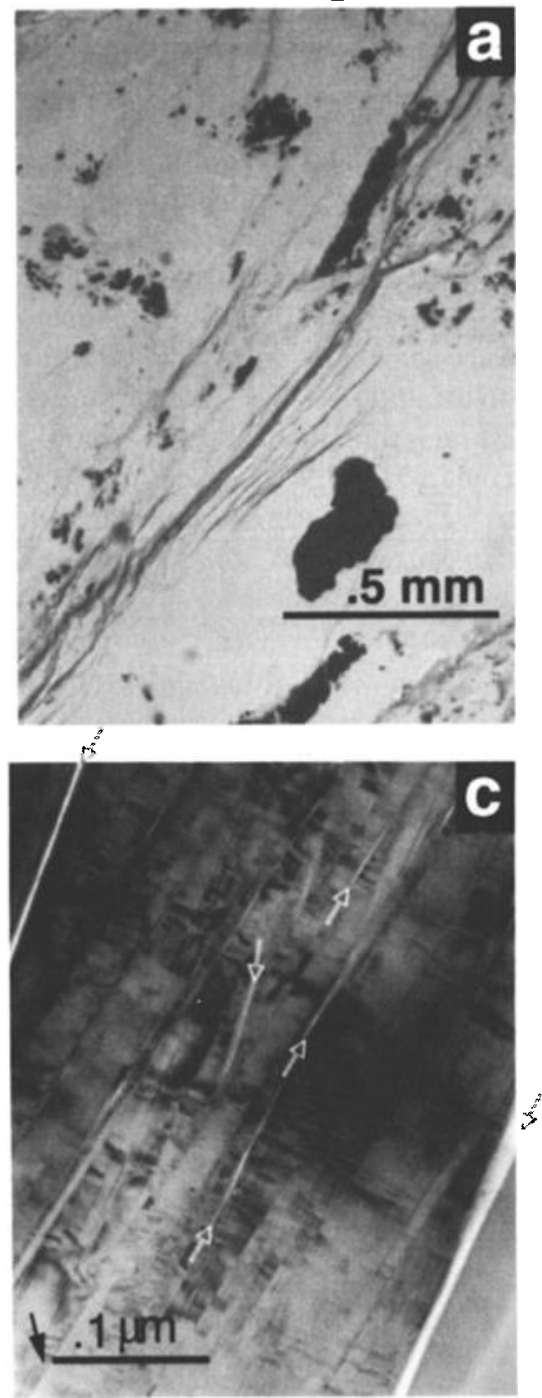

Antigorite, TEM

\section{Antigorite Crossed Nicols}
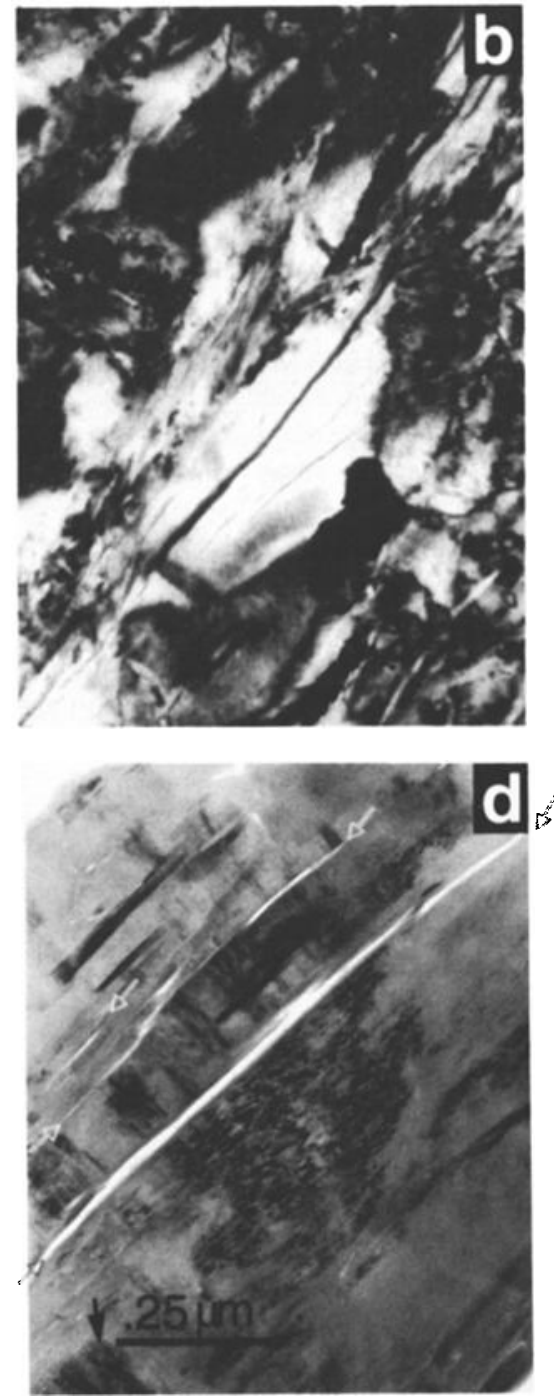

Lizardite, TEM

Figure 10. (a-c) Microstructures of "ductile" samples of antigorite and (d) lizardite deformed at high pressures. Although deformation was macroscopically ductile, the grain-scale microstructure is dominated by microcracks. Plane light and crossed Nicols optical micrographs of a grain-scale shear zone in antigorite (Figures 10a and 10b) display numerous cracks in a zone $\sim 0.2 \mathrm{~mm}$ wide. The cracks form parallel to the mineral cleavage, as confirmed by the TEM micrograph (Figure 10c). Microcracks (open arrows) are at high angles to the shortening direction (black arrow by scale bar). Numerous cracks along grain boundaries and within grains are observed. Lizardite displays similar microstructures at the TEM scale (Figure 10d); deformation is dominated by intragranular and grain boundary microcracks parallel to (001) cleavage. Microstructural observations did not show evidence for plastic deformation (microkinking, dislocation glide). The micrographs correspond to samples a-25 (Figures 10a and 10b), a-24 (Figure 10c), and 1-39 (Figure 10d). Compression direction in Figure 10a and 10b is vertical.

the (001) cleavage are shown in Figures $10 \mathrm{c}$ and $10 \mathrm{~d}$. The microcracks form at high angles to the shortening direction, consistent with the orientation of the small-scale shear zones observed optically. Zones of uncracked material are scarce, both at optical and TEM scales, emphasizing the distributed nature of deformation in this regime.

\section{Plastic Deformation Microstructures}

Crystal plastic deformation does not appear to contribute significantly to strain in lizardite and antigorite in either the localized or the distributed deformation regimes. There is no resolvable difference between the density of dislocations or twins in undeformed and deformed samples. However, because the 

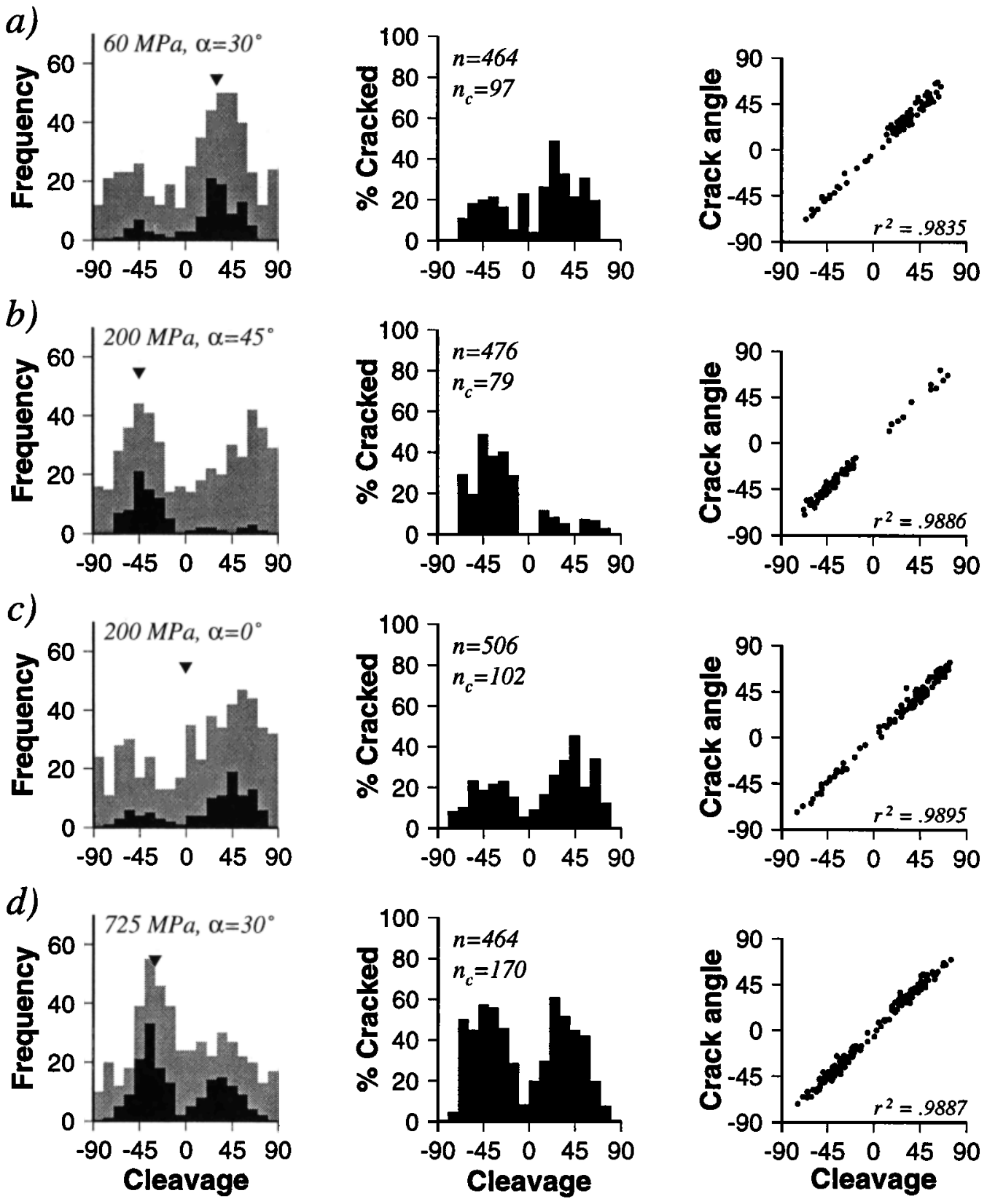

Figure 11. Histograms of the orientation of the (001) cleavage and cracks in deformed antigorite. The angle of the (001) cleavage of individual grains with respect to $\sigma_{1}$ is shown on the left (gray shading). The black shaded regions show the number and orientation of grains associated with either an intragranular or grain boundary crack. The percentage of cracked grains for each orientation bin is shown in the center. The orientation of cracks is plotted versus the orientation of the cleavage on the right. These data demonstrate that cracking occurs almost exclusively parallel to the (001) cleavage $\left(r^{2}>0.98\right.$ in all cases). In each case the total number of measurements $n$ and the number of cracked grains $n_{c}$ are indicated. With increasing pressure (Figures 11a to 11d) the total percentage of cracked grains increases, and the anisotropy in the orientation of the cracked grains decreases, consistent with a transition from localized to distributed deformation.

microstructure of the starting materials is complex (Figure 1), we cannot rule out the possibility that some plastic deformation occurred without significantly changing the density of crystal defects. Further evidence for a lack of crystal plasticity is given by a comparison of microstructures in serpentinites to those in biotite schists deformed at similar conditions. Biotite, which has a crystal structure similar to that of serpentine, deforms plastically at room temperature and develops kink bands associated with dislocation glide on the basal plane [Shea and
Kronenberg, 1992]. Such kink bands were not observed in any of the deformed serpentinite samples.

\section{Microcrack Orientations}

The orientation of microcracks relative to both the shortening direction and the (001) cleavage was measured optically in antigorite samples deformed in both the localized and distributed regimes. The small grain size of lizardite did not permit similar studies. However, the similarity between the microstructures of 
antigorite and lizardite at the TEM scale suggests that results obtained from antigorite are representative of processes operating in lizardite. For each thin section a regular grid with $0.5 \mathrm{~mm}$ spacing was defined; at each grid point we (1) measured the orientation of the (001) cleavage of the grain, (2) determined if the grain was cracked, and (3) measured the crack orientation for those grains that were cracked. All orientations are given with respect to the shortening direction. In each sample more than $\mathbf{4 5 0}$ measurements were made (Figure 11).

The strong control that the $(001)$ cleavage of serpentine imparts on the formation of microcracks is illustrated by plots on the right of Figure 11. In all cases the orientation of microcracks coincides with that of the cleavage $\left(r^{2}>0.98\right)$, demonstrating that microcracks form almost exclusively parallel to the (001) cleavage.

Deformation is dominantly accommodated by shear on microcracks as opposed to opening and propagation of axial microcracks at all pressures. Histograms of frequency of cracked grains versus their orientation show that cracked grains are dominantly oriented $>20^{\circ}$ from $\sigma_{1}$, mostly between $30^{\circ}$ and $60^{\circ}$ (plots on left side of Figure 11). The weak lattice preferred orientation (LPO) of antigorite may contribute to the distribution of microcracks. However, normalized histograms demonstrate that the percentage of cracked grains in a particular orientation is higher at high angles to the shortening direction (center of Figure 11).

With increasing confining pressure the percentage of cracked grains increases and the anisotropy of crack orientation decreases. Both changes are associated with the transition from localized to distributed deformation. At $P_{c}=50$ and $200 \mathrm{MPa}$, less than $20 \%$ of the grains are cracked, while at $750 \mathrm{MPa},>35 \%$ of the grains are cracked, consistent with the transition from localized to distributed deformation shown in Figure $4 \mathrm{~b}$. This increase in microcrack density is also accompanied by a marked change in the orientation of the microcracks. In the lower-pressure samples (Figures 11a-11c), microcracks are mostly oriented parallel to the fault. In contrast, in the high-pressure run the microcracks are distributed symmetrically about $0^{\circ}$ (Figure 11d).

\section{Discussion}

\section{Nondilatant Brittle Deformation by Shear Microcracking}

The non-dilatant nature of brittle deformation of serpentinites is consistent with the observation that deformation is accommodated by shear microcracking. It is well documented that dilatant brittle deformation is associated with the opening of mode I (axial) microcracks [e.g., Wong, 1982]. However, significant axial microcracking is not observed in serpentinites even at confining pressures as low as $50 \mathrm{MPa}$ (Figure 11). Because creation of void space along a shear crack is restricted to irregularities along the shear plane, this crack geometry is less effective in causing dilatancy than the opening of mode I microcracks.

Although limited dilation or compaction was detected in some runs, several lines of evidence suggest that volumetric strain measurements are influenced by inhomogeneous deformation associated with faulting. Strain measurements during and after localization are representative only of deformation in the vicinity of the strain gauges. Thus volumetric strain behavior after strain localization is not known as it cannot be measured accurately with strain gauges. In addition, optical inspection of the jackets of six deformed samples (1-46, 1-47, 1-48, 1-49, a-57, and 1-58) shows that faults localized directly beneath one (1-46, 1-47, l-48) or both of the strain gauges (1-49, a-57, 1-58). Finally, stressstrain curves also provide evidence for fault-induced inhomogeneous strain. For example, the curve for 1-55 (Figure 7b) indicates that apparent dilation is caused by a sudden decrease in radial strain immediately prior to failure. This abrupt change is not accompanied by a similar change in the axial strain, as would be expected during homogeneous inelastic deformation.

The apparent compaction observed during some experiments on serpentinites cannot be attributed to pore collapse. Rocks with more than $\sim 5 \%$ porosity (e.g., sandstones) may display compaction during the initial part of the loading cycle, but ultimately dilate when strain localization occurs [e.g., Brace, 1978; Wong, 1990]. In contrast, serpentinites show limited compaction or dilation immediately prior to failure. Examination of the starting materials using both optical and TEM microscopy demonstrates that the porosity of undeformed lizardite samples is $<0.5 \%$, and that the antigorite serpentinite samples have no resolvable porosity. In addition, deformed samples lack microstructures typical of pore collapse, such as damage zones around pores, or cracks originating at pores [e.g., Hirth and Tullis, 1989; Wong, 1990; Zhang et al., 1990].

The lack of microstructural evidence for both pore collapse (compaction) and axial microcracking (dilation) indicates that the actual permanent volumetric strain in serpentinites is very small. The high values of $c^{\prime} / \sigma_{\max }$ suggest that strain localization occurs immediately prior to failure, consistent with studies on granite and sandstone that demonstrate that strain localization occurs near $\sigma_{\max }$ [Lockner et al., 1992; Wong, 1982]. Thus the small amounts of dilatancy and/or compaction in serpentinites may reflect inhomogeneous strains associated with faulting and not volumetric strain associated with shear microcracking.

\section{Brittle Deformation Regimes and Implications for Mohr- Coulomb Theory}

Brittle deformation regimes can be defined by the operation of different deformation processes. For example, while this study shows that shear microcracking dominates deformation of serpentinites, granite and quartzite show extensive axial microcracking at confining pressures less than $\sim 750 \mathrm{MPa}$ [e.g., Wong, 1982; Hirth and Tullis, 1994]. Similarly, while crystal plasticity does not appear to contribute to the deformation of serpentinites, it is an important process during room temperature deformation of calcite marble and mica-schist [e.g., Fredrich et al., 1989; Shea and Kronenberg, 1992]. In the case of calcite marble, semibrittle deformation occurs between $P_{c} \sim 30$ and $P_{c} \sim$ $300 \mathrm{MPa}$ (brittle to semibrittle and semibrittle to plastic transitions, respectively). Mica schists show little or no pressure dependence of strength at $P_{c}>200$ [Shea and Kronenberg, 1992]. Although dislocation glide is the dominant deformation mechanism in mica schists, some brittle deformation microstructures such as voids and cracks associated with kinks are observed in the pressure-insensitive regime (200 $\mathrm{MPa}<P_{c}<$ $500 \mathrm{MPa}$ ).

These different deformation regimes can be separated by plotting $\sigma_{y} / \sigma_{\max }$ versus $c^{\prime} / \sigma_{\max }$ (Figure 12). The field labeled "Axial cracks" is characteristic of rocks in which deformation is accommodated by axial microcracking with no crystal plasticity (e.g., granite). Experimental data for granite plot at low values of $c^{\prime} / \sigma_{\max }$ because permanent volumetric strain is achieved well before $\sigma_{\max }$; in addition, significant yielding (as indicated by deviation of the stress-axial strain curve from linearity) does not occur in the mode I regime until microcracking substantially damages the sample. Thus the stress-axial strain curves for 


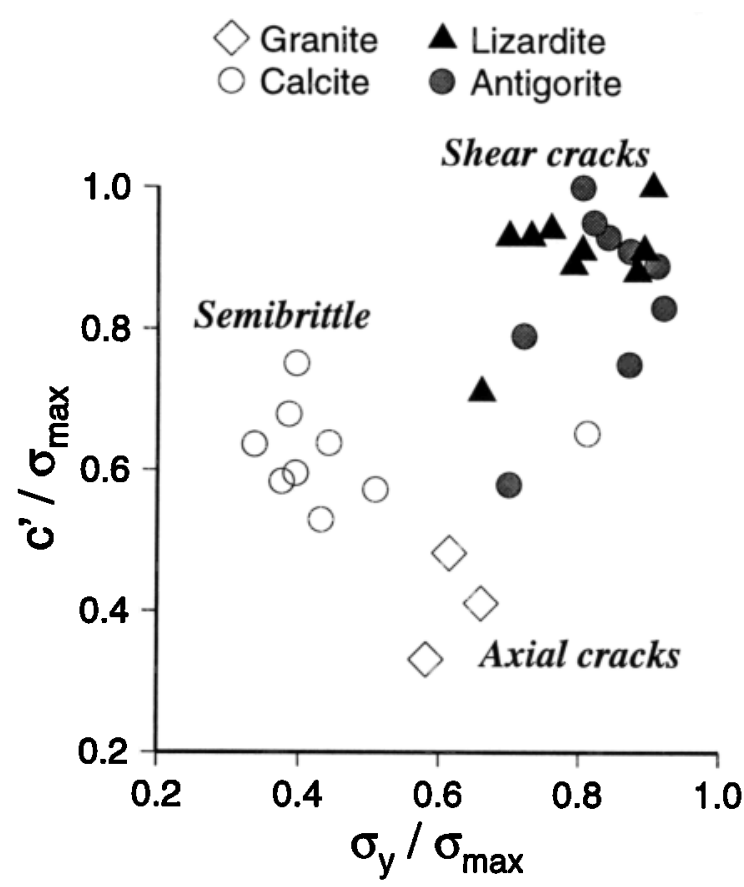

Figure 12. Plot of $c^{\prime} / \sigma_{\max }$ versus $\sigma_{y} / \sigma_{\max }$ showing brittle deformation regimes defined by the mechanical response to the style of microcracking, and the activation of crystal plasticity. The field labeled "Axial cracks" is characteristic of rocks in which deformation is accommodated by axial microcracking with no crystal plasticity. Deformation in the "Semibrittle" regime is characterized by values of $c / \sigma_{\max }>\sigma_{y} / \sigma_{\max }$ because the initial yielding is accommodated by crystal plastic mechanisms. The field labeled "Shear cracks" shows the unique behavior exhibited by the serpentinites. Both polytypes have high values of $c^{\prime} / \sigma_{\max }$ because brittle deformation is dominated by shear microcracking. In addition, the apparent lack of crystal plastic deformation is indicated by values of $\sigma_{y} / \sigma_{\max } \approx c^{\prime} / \sigma_{\max }$.

granite indicate $c^{\prime} / \sigma_{y}<1$. This observation demonstrates that axial stress-strain curves are not a sensitive indicator of the initiation of permanent deformation [e.g., Brace et al., 1966]. In Figure 12 this situation is reflected by values of $\sigma_{y} / \sigma_{\max }>$ $c ' / \sigma_{\max }$.

Deformation in the semibrittle regime is characterized by values of $c^{\prime} / \sigma_{y}>1$ because the initial yielding is accommodated by plastic mechanisms including twinning or dislocation glide. For example, in calcite marble deformed in the semibrittle regime, $c^{\prime} / \sigma_{y}$ increases from $\sim 1$ to $\sim 2$ with increasing confining pressure from 50 to $300 \mathrm{MPa}$ [Fredrich et al., 1989]. As illustrated in Figure 12, semibrittle deformation of marble is therefore characterized by $c^{\prime} / \sigma_{\max }>\sigma_{y} / \sigma_{\max }$. At these conditions, the brittle component of deformation is accommodated mostly by axial microcracking. Thus the calcite marble data plot at relatively low values of $\sigma_{y} / \sigma_{\max }$.

The field labeled "shear cracks" in Figure 12 shows the unique behavior exhibited by the serpentinites. Both polytypes of serpentine have high values of $c^{\prime} / \sigma_{\max }$ because brittle deformation is dominated by shear microcracking. In addition, the apparent lack of crystal plastic deformation is evident from values of $\sigma_{y} / \sigma_{\max } \approx c^{\prime} / \sigma_{\max }$, in contrast to the data for calcite marble that show $c^{\prime} / \sigma_{\max }>\sigma_{y} / \sigma_{\max }$. Consequently, serpentinites tend to plot at higher values of $c^{\prime} / \sigma_{\max }$ and $\sigma_{y} / \sigma_{\max }$ than rocks that deform in the semi-brittle or mode I (axial cracks) regimes.

The Mohr failure envelopes in Figure 6 a demonstrate that the pressure dependence of strength for serpentinite and granite are approximately the same at normal stresses greater than $\sim 1000$ $\mathrm{MPa}$. For example, $\mu_{i}$ for granite decreases from $\sim 0.8$ to $\sim 0.43$ with increasing $\sigma_{n}$, reaching a value relatively similar to the $\mu_{\text {, }}$ $\sim 0.35$ determined for antigorite and lizardite. Such a decrease in the pressure dependence of strength is often related to gradual enhancement of crystal plasticity with increasing pressure [e.g., Paterson, 1978]. Alternatively, this decrease may result from the enhancement of shear microcracking because such deformation requires less work against the confining pressure. This interpretation is supported by the lack of crystal plasticity in granite deformed at room temperature [e.g., Tullis and Yund, 1977]. In addition, a transition from axial to shear microcracking has previously been identified at $P_{c}>600 \mathrm{MPa}$ in quartz aggregates [Hirth and Tullis, 1994] and at $P_{c} \sim 1000 \mathrm{MPa}$ at $T<300^{\circ} \mathrm{C}$ in feldspar aggregates [Tullis and Yund, 1992].

The low pressure dependence of strength of serpentinites at $P_{c}<200 \mathrm{MPa}$ (Figure 6a) is consistent with the observation that deformation is accommodated by shear microcracking at these conditions. We conclude that this behavior is primarily a manifestation of the relative ease of cracking on the (001) cleavage. Microstructural observations indicate that rupture and sliding along the $(001)$ cleavage in serpentine grains oriented at high angles to $\sigma_{1}$ is easier than the opening of axial microcracks (Figure 11). These observations indicate that the fracture energy of the (001) cleavage in serpentinites is low compared with the cleavages of other minerals (e.g., feldspars).

\section{Brittle-Ductile Transition}

Three observations indicate that the transition from localized to distributed deformation in serpentinites corresponds to a change in deformation mechanism from brittle faulting to cataclastic flow. First, no conclusive evidence for crystal plastic deformation was found in any of the deformed samples. Second, both the maximum and the yield stress of both polytypes depend positively on pressure up to $P_{c} \sim 1 \mathrm{GPa}$. Third, numerous shear microcracks were present in samples deformed at the highest confining pressures. A transition from faulting to cataclastic flow is observed in feldspar aggregates, at $P_{c} \sim 500 \mathrm{MPa}$ and $T \sim 300^{\circ} \mathrm{C}$ [Tullis and Yund, 1992]. Microstructural observations indicate that cataclastic flow in feldspar is also accommodated by shear microcracks. However, unlike serpentinites, an increase in temperature is required to promote the transition to cataclastic flow.

A transition from localized to distributed deformation is often observed when the strength $\left(\sigma_{\max }\right)$ of a material becomes less than Byerlee's friction law [e.g., Evans et al., 1990, and references therein]. The results on serpentinite indicate that, more generally, this criterion should incorporate the friction law derived for each rock type instead of Byerlee's law. For example, while deformation of lizardite remains localized at stresses below that predicted by Byerlee's law at $P_{c}$ between 100 and $200 \mathrm{MPa}$, the transition from faulting to cataclastic flow occurs at the crossover of $\sigma_{\max }$ and the friction law of lizardite (Figure 4c).

It is also commonly accepted and observed that fully plastic deformation occurs when the strength of a rock is less than the confining pressure (Goetze's criterion [e.g., Evans et al., 1990; Kohlstedt et al., 1995]). Although the strength of lizardite at $P_{c}>$ 
$300 \mathrm{MPa}$ is approximately the same as the confining pressure (Figure $4 \mathrm{~b}$ ), no conclusive evidence for crystal plasticity has been found. The observation that the yield stress of these samples is less than the confining pressure (i.e., $\sigma_{y}<P_{c}$ ) therefore suggests that microcracks nucleated within the regime of assumed plastic deformation $\left(\sigma_{\max }<P_{c}\right)$. The low fracture strength of the (001) cleavage presumably allows the development of brittle deformation even when the applied differential stress is similar to or less than the confining pressure.

\section{Rheology of Shear Zones and the Tectonic Evolution of Oceanic Lithosphere}

The onset of dilatancy is often assumed to impart important controls on the mechanical behavior of fault zones in the presence of fluids [e.g., Sleep and Blanpied, 1992; Lockner and Byerlee, 1994; Segall and Rice, 1995]. In contrast, the lack of significant dilatancy during deformation of serpentinites may result in unique behavior. For example, such behavior would suppress dilatancy hardening. In addition, the geometry of microcracking in serpentinites might favor the confinement of fluids within the shear zone. Natural serpentinite shear zones commonly display a fabric with the (001) cleavage oriented parallel to the fault plane [e.g., Harding, 1987; Norrell et al., 1989; Hoogerduijn Strating and Vissers, 1994]. Based on our microstructural observations (Figures 9-11), microcracks in such shear zones would be expected to form parallel to the grain boundaries and/or the (001) cleavage, and thus parallel to the fault plane. Although other variables must be considered (e.g., temperature, high strain deformation, and variations in strain rate), such a crack network could limit permeability perpendicular to the fault surface and perhaps increase permeability in directions parallel to the fault plane. Thus elevated pore fluid pressure may be maintained during brittle deformation, and this, combined with the weak rheology of serpentinites, could significantly reduce the strength of serpentine-bearing faults.

The oceanic lithosphere may be substantially weakened when serpentinization occurs. The amount of weakening resulting from the alteration of stronger peridotite to weaker serpentinite depends on the degree of serpentinization of the mantle lithosphere, the serpentine polytype, and the maximum depth of serpentinization. The maximum strength of partially serpentinized peridotite appears to be comparable to that of serpentinite [Brace et al., 1966]. Consequently, even small amounts of serpentinization of the mantle could substantially weaken the rock. Oceanic serpentinites, which are nearly all composed mostly of lizardite [e.g., Aumento and Loubat, 1971], are often dredged in the vicinity of the ridge axis of slow spreading ridges [e.g., Aumento and Loubat, 1971; Karson et al., 1987; Bonatti and Michael, 1989; Dick, 1989; Tucholke and Lin, 1994], indicating that serpentinization can occur in very young ( $<1 \mathrm{Ma}$ ) lithosphere at slow spreading ridges. Therefore tectonic processes along the walls of the axial valley and within transform faults may be controlled by the rheology of serpentinized peridotite, particularly in the vicinity of discontinuities at slow spreading ridges, where the "magmatic" crust is thin, discontinuous or nonexistent [e.g., Lin et al., 1990; Tolstoy et al., 1993; Tucholke and Lin, 1994; Cannat et al., 1995].

\section{Conclusions}

Deformation experiments conducted on intact cores of serpentinite demonstrate that antigorite and particularly lizardite are weaker than other common lithospheric rocks. A transition from localized (faulting) to distributed (ductile) deformation occurs for both polytypes with increasing confining pressure at room temperature. In lizardite, this transition occurs at $\sim 200-400$ $\mathrm{MPa}$, while in antigorite it is observed at $\sim 400 \mathrm{MPa}$. Deformation in the ductile regime is accommodated by cataclastic flow. The transition from localized to distributed deformation in lizardite occurs at the crossover between the strength of intact lizardite and the friction law unique to lizardite. This observation emphasizes that the use of Byerlee's law to define the brittle-ductile transition must be done with caution.

Volumetric strain measurements indicate that brittle deformation of both serpentine polytypes is mostly nondilatant. Microstructural observations show that microcracks form almost exclusively parallel to the (001) cleavage of individual serpentine grains. In addition, microcracks form dominantly at high angles to the shortening direction indicating that brittle deformation is accommodated mostly by shear microcracking, consistent with the observed lack of dilatancy. The low strength and low pressure dependence of strength of serpentinites can be attributed to this nondilatant style of brittle deformation and a low fracture strength of the (001) cleavage. Mohr envelopes demonstrate that brittle deformation accommodated by shear microcracking displays a lower pressure dependence than that accommodated by axial microcracking.

The mechanical behavior of serpentinites can result in extremely weak fault zones in the oceanic lithosphere. The weak nature of serpentine, lizardite in particular, and the nondilatant nature of brittle deformation can result in substantial weakening of serpentine-bearing faults relative to the surrounding country rock. In areas such as slow spreading ridges, serpentinization of the lithospheric mantle could play a major role on its tectonic evolution.

\section{Notation}

$c^{\prime}$ Differential stress at the onset of dilation (MPa).

$P_{c} \quad$ Confining pressure $(\mathrm{MPa})$.

$T$ Temperature $\left({ }^{\circ} \mathrm{C}\right)$.

$\alpha \quad$ Angle between foliation and shortening direction, deg.

$\varepsilon_{a} \quad$ Axial strain.

$\varepsilon_{r} \quad$ Radial strain.

$\varepsilon_{v} \quad$ Volumetric strain, $\varepsilon_{v}=\varepsilon_{a}+2 \varepsilon_{r}$.

$\varepsilon_{e} \quad$ Extrapolated elastic strain at failure.

$\Delta \varepsilon_{v} \quad$ Permanent volumetric strain, $\Delta \varepsilon_{v}=\varepsilon_{v}-\varepsilon_{e}$

$\mu$ Coefficient of friction.

$\mu_{1} \quad$ Coefficient of internal friction.

$\sigma_{\max }$ Maximum or peak differential stress $\left(\sigma_{1}-\sigma_{3}\right)$, "strength" (MPa).

$\sigma_{\mathrm{n}} \quad$ Normal stress (MPa)

$\sigma_{\mathrm{m}} \quad$ Mean stress $\left(\left[\sigma_{1}+\sigma_{2}+\sigma_{3}\right] / 3\right)(\mathrm{MPa})$.

$\sigma_{y} \quad$ Differential stress at yield point (MPa).

$\tau \quad$ Shear stress $(\mathrm{MPa})$.

Acknowledgments. We are grateful to J. Hirst, S. Karner, A. Post, and $\mathrm{G}$. Siddiqi for assistance during the experiments, and especially to $\mathrm{H}$. J. B. Dick, P. Kelemen, N. Shimizu, J. Tullis, and R. Yund for generously allowing us to use their facilities. We thank H. J. B. Dick and T. Tullis for providing rock specimens. In addition, we would like to thank $E$. Hooft, G. Jaroslow, J. Lin, C. Marone, G. Siddiqi, D. Smith, B. Tucholke, J. Tullis, T. Tullis, and D. Yund for numerous helpful discussions, comments and suggestions. Finally, we thank J. Tullis for comments on the submitted manuscript, and A. Kronenberg, L. Reinen, and G. Harper for their thoughtful reviews that helped us to clarify our arguments The GMT software [Wessel and Smith, 1991] was extensively used. This work was supported by NSF grants OCE-9313812 and OCE 9314103 . Woods Hole Oceanographic Institution contribution 9167. 


\section{References}

Aumento, F., and $\mathrm{H}$. Loubat, The mid-Atlantic ridge near $45^{\circ} \mathrm{N}$ : Serpentinized ultramafic intrusions, Can. J. Earth Sci., 8, 631-663, 1971.

Bonatti, E., Serpentinite protrusions in the oceanic crust, Earth Planet. Sci. Lett., 32, 107-113, 1976.

Bonatti, E., and P. J. Michael, Mantle peridotites from continental rifts to ocean basins to subduction zones, Earth Planet. Sci. Lett., 91, 297$311,1989$.

Brace, W. F., Some new measurements of linear compressibility of rocks, J. Geophys. Res., 70, 5669-5678, 1965.

Brace, W. F., Volume changes during fracture and frictional sliding: A review, Pure Appl. Geophys., 116, 603-614, 1978.

Brace, W. F., and D. L. Kohlstedt, Limits on lithospheric stress imposed by laboratory experiments, J. Geophys. Res., 85, 6248-6252, 1980.

Brace, W. F., B. W. Paulding Jr., and C. Scholz, Dilatancy in the fracture of crystalline rocks, J. Geophys. Res., 71, 3939-3953, 1966.

Brodie, K. H., and E. H. Rutter, On the relationship between deformation and metamorphism, with special reference to the behavior of basic rocks, in Kinematics, Textures and Deformation, edited by A. B. Thompson and D. Rubie, Adv. Phys. Geochem., 4, 138-179, 1985.

Byerlee, J., Friction of rocks, Pure Appl. Geophys., 116, 615-626, 1978.

Cannat, M., D. Bideau, and $\mathrm{H}$. Bougault, Serpentinized peridotites and gabbros in the Mid-Atlantic Ridge axial valley at $15^{\circ} 37^{\prime} \mathrm{N}$ and 16 $52 \mathrm{~N}$, Earth Planet. Sci. Lett., 109, 87-106, 1992.

Cannat, M. et al., Thin crust, ultramafic exposures, and rugged faulting patterns at the Mid-Atlantic Ridge $\left(22^{\circ}-24^{\circ} \mathrm{N}\right)$, Geology, 23, 49-52, 1995.

Caruso, L. J., and J. V. Chemosky, The stability of lizardite, Can. Mineral., 17, 757-769, 1979.

Chen, W. P., and P. Molnar, Focal depths of intracontinental and intraplate earthquakes and their implications for the thermal structure and mechanical properties of the lithosphere, J. Geophys. Res., 88, 4183-4214, 1983.

Coleman, R. G., Petrological and geophysical nature of serpentinites, Bull. Geol. Soc. Am., 82, 879-918, 1971.

Coulton, A. J., G. D. Harper, and D. S. O'Hanley, Oceanic versus emplacement age serpentinization in the Josephine ophiolite: Implications for the nature of the Moho at intermediate and slow spreading ridges, J. Geophys. Res., J00, 22,245-22,260, 1995.

Deer, W. A., R. A. Howie, and J. Zussman, An Introduction to the RockForming Minerals, 528 pp., Longman, White Plains, N. Y., 1966.

Dengo, C. A., and J. M. Logan, Implications of the mechanical and frictional behavior of serpentinite to seismogenic faulting, $J$. Geophys. Res., 86, 10,771-10,782, 1981.

Dick, H. J. B., Abyssal peridotites, very slow spreading ridges and ocean ridge magmatism, in Magmatism in the Ocean Basins, edited by A. D. Saunders and M. J. Norry, Geol. Soc. London, Spec. Publ., 42, 71-105, 1989.

Dungan, M. A., Bastite pseudomorphs after orthopyroxene, clinopyroxene and tremolite, Can. Mineral., 17, 729-740, 1979.

Evans, B., J. T. Fredrich, and T.-F. Wong, The brittle-ductile transition in rocks: Recent experimental and theoretical progress, in The brittleductile transition in rocks, the Herd Volume, Geophys. Monogr. Ser., vol. 56, edited by A. Duba, W. B. Durham, J. W. Handin, and H. Wang, pp. 1-20, AGU, Washington, D. C., 1990.

Fredrich, J. T., B. Evans, and T.-F. Wong, Micromechanics of the brittle to plastic transition in Carrara marble, J. Geophys. Res., 94, 4129$4145,1989$.

Gillis, K. M., G. Thompson, and D. S. Kelley, A view of the lower crustal component of hydrothermal systems at the mid-Atlantic ridge, $J$. Geophys. Res., 98, 19,597-19,619, 1993.

Harding, D. J., Josephine peridotite tectonites: A record of upper mantle plastic flow, Ph.D. thesis, 334 pp., Cornell Univ., Ithaca, N. Y., 1987.

Hess, H. H., History of ocean basins, in Petrological Studies: a Volume in Honor of A. F. Buddington, edited by A. E. J. Engel, H. L. James and B. F. Leonard, pp. 599-620, Geol. Soc. Amer., Boulder, Colo., 1962.

Hirth, G., and J. Tullis, The effects of pressure and porosity on the micromechanics of the brittle-ductile transition in quartzite, $J$. Geophys. Res., 94, 17,825-17,838, 1989.

Hirth, G., and J. Tullis, The brittle-plastic transition in experimentally deformed quartz, J. Geophys. Res., 99, 11731-11747, 1994.

Hoogerduijn Strating, E. H., and R. L. M. Vissers, Structures in natural serpentinite gouges, J. Struct. Geol., 16, 1205-1215, 1994.

Janecky, D. R., and W. E. Seyfried, Hydrothermal serpentinization of peridotite within the oceanic crust: Experimental investigations of mineralogy and major element chemistry, Geochim. Cosmochim. Acta, $50,1357-1378,1986$.

Karson, J. A. et al., Along-axis variations in seafloor spreading in the MARK Area, Nature, 328, 681-685, 1987.

Kohlstedt, D. L., B. Evans, and S. J. Mackwell, Strength of the lithosphere: Constraints imposed by laboratory experiments, $J$. Geophys. Res., 100, 17,587-17,602, 1995.

Lin, J., and E. M. Parmentier, Mechanisms of lithospheric extension at mid-ocean ridges, Geophys. J. 96, 1-22, 1989.

Lin, J., G. M. Purdy, H. Schouten, J. C. Sempere, and C. Zervas, Evidence from gravity data for focused magmatic accretion along the Mid-Atlantic Ridge, Nature, 344, 627-632, 1990

Lockner, D. A., and J. D. Byerlee, Dilatancy in hydraulically isolated faults and the suppression of instability, Geophys. Res. Lett, 21, 23532356, 1994.

Lockner, D. A., J. D. Byerlee, V. Kuksenko, A. Ponomarev, and A. Sidorin, Observations of quasistatic fault growth from acoustic emissions, in Fault Mechanics and Transport Properties of Rocks, edited by B. Evans and T.-F. Wong, Pp. 3-31, Academic, San Diego 1992.

Maltman, A. J., Serpentinite textures in Anglesey, North Wales, United Kingdom, Geol. Soc. Am. Bull., 89, 972-980, 1978.

Mével, C., and M. Cannat, Lithospheric stretching and hydrothermal processes in oceanic gabbros from slow spreading ridges, in Ophiolite Genesis and Evolution of the Oceanic Lithosphere, edited by $\mathrm{T}$ Peters, A. Nicolas, and P. G. Coleman, pp. 293-312, Kluwer Acad., Norwell, Mass., 1992

Moody, J. B., An experimental study on the serpentinization of ironbearing olivines, Can. Mineral., 14, 462-478, 1976.

Moore, D., D. A. Lockner, M. Shengli, R. Summers, and J. D. Byerlee, Strength of serpentinite gouges to $200^{\circ} \mathrm{C}$, Eos Trans. $A G U, 76(46)$ Fall Meet. Suppl., 632, 1995.

Murrell, S. A. F., and I. A. H. Ismail, The effect of decomposition of hydrous minerals on the mechanical properties of rocks at high pressures and temperatures, Tectonophysics, 31, 207-258, 1976.

Neumann, G. A., and D. W. Forsyth, The paradox of the axial profile: Isostatic compensation along the axis of the Mid-Atlantic Ridge?, $J$. Geophys. Res., 98, 17,891-17,910, 1993

Norrell, G. T., A. Teixell, and G. D. Harper, Microstructure of serpentine mylonites from the Josephine ophiolite and serpentinization in retrogressive shear zones, California, Geol. Soc. Am. Bull., 101, 673$682,1989$.

O'Hanley, D. S., Serpentinites: Records of Tectonic and Petrological History, Oxford Monogr. Geol. Geophys., no. 34, 277 pp., Oxford Univ., New York, 1996.

O'Hanley, D. S., J. V. Chernosky, and F. J. Wicks, The stability of lizardite and chrysotile, Can. Mineral., 27, 483-493, 1989.

Paterson, M. S, Experimental Rock Deformation: The Brittle Field, 254 pp., Springer-Verlag, New York, 1978.

Raleigh, C. B., and M. B. Paterson, Experimental deformation of serpentinite and its tectonic implications, J. Geophys. Res., 70, 39653985,1965 .

Reinen, L. A., and T. E. Tullis, Microstructural evidence of strain localization and distributed strain in serpentinite friction experiments, Eos Trans. AGU, 76(46), Fall Meet. Suppl., 560, 1995.

Reinen, L. A., J. D. Weeks, and T. E. Tullis, The frictional behavior of lizardite and antigorite serpentinites: Experiments, constitutive models, and implications for natural faults, Pure Appl. Geophys. , 143, 318-358, 1994

Sano, O., I. Ito, and $M$. Terada, Influence of strain rate on dilatancy and strength of Oshima granite under uniaxial compression, $J$. Geophys. Res., 86, 9299-9311, 1981.

Segall, P., and J. R. Rice, Dilatancy, compaction, and slip instability of a fluid-infiltrated fault, J. Geophys. Res., 100, 22,155-22,171, 1995.

Shea, W. T., and A. K. Kronenberg, Rheology and deformation mechanisms of an isotropic mica schist, $J$. Geophys. Res., 97, 15,201$15,237,1992$.

Shimada, M., and A. Cho, Two types of brittle fracture of silicate rocks under confining pressures and their implications in the Earth's crust, Tectonophysics, 175, 221-235, 1990.

Sleep, N., and M. L. Blanpied, Creep, compaction and the weak rheology of major faults, Nature, 359, 687-692, 1992.

Tolstoy, M., A. J. Harding, and J. A. Orcutt, Crustal thickness on the Mid-Atlantic ridge: Bull's eye gravity anomalies and focused accretion, Science, 262, 726-729, 1993. 
Tucholke, B. E., and J. Lin, A geological model for the structure of ridge segments in slow spreading ocean crust, J. Geophys. Res., 99, 11,93711,958, 1994.

Tullis, J., and R. A. Yund, Experimental deformation of dry Westerly granite, J. Geophys. Res., 82, 5705-5718, 1977.

Tullis, J., and R. Yund, The brittle-ductile transition in feldspar aggregates: An experimental study, in Fault Mechanics and Transport Properties of Rock, edited by B. Evans and T.-F. Wong, pp. 89-117, Academic, San Diego, Calif., 1992.

Ulmer, P., and V. Trommsdorff, Serpentine stability to mantle depths and subduction-related magmatism, Science, 268, 858-861, 1995.

Vernon, R. H., Relationship between microstructures and metamorphic assemblages, Tectonophysics, 39, 439-452, 1977.

Wessel, P., and W. H. F. Smith, Free software helps map and display data, Eos Trans. $A G U, 72(41), 445-446,1991$.

Wicks, F. J., and D. S. O'Hanley, Serpentine minerals: Structures and petrology, in Hydrous Phyllosilicates (exclusive of micas), edited by S. W. Bailey, Rev. Mineral., 19, 91-167, 1988.

Wicks, F. J., and E. J. W. Whittaker, Serpentine textures and serpentinization, Can. Mineral., 15, 459-488, 1977.

Wicks, F. J., E. J. W. Whittaker, and J. Zussman, An idealized model for serpentine textures after olivine, Can. Mineral., 15, 446-458, 1977.
Wong, T.-F., Micromechanics of faulting in Westerly granite, Int. J. Rock Mech. Min. Sci., 19, 49-64, 1982.

Wong, T.-F., Mechanical compaction and the brittle-ductile transition in porous sandstones, in Deformation Mechanisms, Rheology and Tectonics, edited by R. J. Knipe and E. H. Rutter, Geol. Soc. Spec. Publ., 54, 111-122, 1990.

Zhang, J., T.-F. Wong, and D. M. Davis, Micromechanics of pressureinduced grain crushing in porous rocks, $J$. Geophys. Res., 95, 345-352, 1990.

J. Escartin, Department of Geological Sciences, University of Durham, South Road, Durham, DH1 3LE, England. (email: javier.escartin@durham.ac.uk)

B. Evans, Earth, Atmospheric and Planetary Sciences, Massachusetts Institute of Technology, Rm 54-718, Cambridge, MA 02139. (email: brievans@mit.edu)

G. Hirth, Department of Geology and Geophysics, Woods Hole Oceanographic Institution, MS 8, McLean, Woods Hole, MA 02543. (email: ghirth@whoi.edu)

(Received April 22, 1996; revised September 3, 1996; accepted September 10, 1996.) 